\title{
ECOLOGICAL-ECONOMIC BALANCE IN FINING ENVIRONMENTAL POLLUTION SUBJECTS BY A DYADIC 3-PERSON GAME MODEL
}

\author{
ROMANUKE, V. V. \\ Faculty of Navigation and Naval Weapons, Polish Naval Academy \\ 69 Śmidowicza Street, 81-127 Gdynia, Poland \\ (e-mail: romanukevadimv@gmail.com) \\ (Received $6^{\text {th }}$ Oct 2018; accepted $28^{\text {th }}$ Nov 2018)
}

\begin{abstract}
A problem of rationalizing industrial wastewater treatment is considered. It issues from that industrial enterprises may violate conventions about water treatment, so then they are fined. Those fines are directed to control water pollution by measuring it and treating wastewater additionally, if necessary. Under threat of heavy fines, however, an enterprise may reduce or stop its manufacturing resulting in a budget cut for water resources conservation and recirculation. Therefore, fining for under-treating industrial wastewater is balanced using an environmental protection model in the form of a dyadic 3-person game. According to this game, in which three subjects of water pollution (industrial enterprises) are obliged to treat industrial wastewater, the ecologically healthy water balance of the reservoir does not worsen if just one subject does not apply the treatment. Such model implies that about one third of the polluted water recovers without treatment. If none of the subjects applies a water treatment system, they are fined (with a 3-fine for each). If only two subjects do not treat wastewater, all the three subjects are fined (with a 2-fine for each) due to impossibility of finding those two violators. Application of a water treatment system costs a conventional unit for each subject per a period of time (a day, a week, or a month). The game solution is searched on the regular finite lattice of situations, which is obtained by sampling the continuous set of those situations. Dealing with either non-symmetric or non-profitable situations, an approximate solution is found using concessions in the equilibrium. By this solution, the water treatment system is turned off for 3 periods of 10 , and the 2-fine is optimally set at 0.34 units, whereas the 3 -fine is set at 1.394 units. Under threat of the heavy 3 -fine, the subjects will definitely come to a convention of scheduling the water treatment systems. Switching from "clean" to "polluting" manufacturing and backwards is to be controlled exactly once per those 10 periods. Eventually, the cost of 8.018 units for a subject is just the expected spending, whereas the least cost in 7 units is still possible under the corresponding water treatment schedule.
\end{abstract}

Keywords: industrial wastewater, water treatment, fining, dyadic game, equilibrium situations

\section{Introduction}

Water resources are intensively used in industries. For their conservation and recirculation, subjects of water pollution are obliged to treat industrial wastewater. The treatment should be executed as much as needed for maintaining the ecologically healthy water balance. A part of polluted water recovers without treatment (Beiras, 2018; Parimal, 2017).

Some industrial enterprises may violate conventions about water treatment. Then the government fines them for under-treating wastewater. Those fines are directed to control water pollution by measuring it and treating additionally, if necessary (Jiménez et al., 2018; Rey et al., 2018). In a certain sense, fining for under-treating is a way for strengthening the state treasury. However, an enterprise may reduce or stop its activity (manufacturing) under threat of heavy fines. The treasury subsequently will receive less. Then a budget for water resources conservation and recirculation will be cut. Therefore, fining for under-treating industrial wastewater should be balanced (Arguedas, 2013; Heyes, 2000; Regens et al., 1997). 
Currently an imbalance in a water treatment convention is a common phenomenon. Primarily, this is about the absence of compelling factors which would force parties to comply with a convention. For instance, the Convention on the Protection and Use of Transboundary Watercourses and International Lakes, also known as the Water Convention, has a joint ad hoc expert group on water and industrial accidents (see [unece.org/env/water.html]). This group deals with the prevention of the accidental pollution of transboundary waters. There is a Protocol on civil liability for damage and compensation caused by transboundary effects of industrial accidents on transboundary waters. Its aim is to give individuals affected by the transboundary impact of industrial accidents on international watercourses a legal claim for adequate and prompt compensation. The financial limits of liability as well as the minimum amount of financial securities have been agreed by all the actors of the Protocol negotiation, including the insurance sector. Despite this, the Protocol has been ratified only by Hungary and it is not in force. The Protocol will enter into force once 16 states have ratified it. This is a partial but demonstrative evidence of the force lack in a convention. But it is obvious that such conventions can be reinforced by financial influence. Therefore, the role of budgeting to achieve a balance in a water treatment convention is principal (Heyes, 2000; James, 2017; Wolf, 2009).

\section{An environmental protection model in the form of a dyadic 3-person game}

A lot of economical factors influence how the budget for water resources conservation and recirculation is formed (Sgroi et al., 2018; Cui et al., 2018; Zikos and Hagedorn, 2017). So, no exact formulae exist for counting the fines. Only simple and rough models can be economically reliable and practically executable (Zomorodian et al., 2018; Regens et al., 1997; Arguedas, 2013). One of such models is a 3-person dyadic game firstly considered by Vorob'yov (1984). According to this game model, three enterprises manufacturing roughly the same production use similar water resources of a reservoir. The used water is polluted through the manufacturing process (e.g. it is shown by Skouteris et al., 2018; Hussain and Wahab, 2018; Mousavi et al., 2015). Sometimes an enterprise is called an environmental pollution subject. Application of a water treatment system costs a conventional unit for each subject per a period of time (a day, a week, or a month). If just a one subject does not apply the treatment, it does not worsen the ecologically healthy water balance of the reservoir owing to recovering. Such model implies that about one third of the polluted water recovers without treatment. If two or three subjects do not apply the treatment, then the polluted water cannot recover and all the three subjects are fined. Along with the fundamental research by Vorob'yov (1984), the fine set at 3 units was also researched by Romanuke $(2009$, 2010a) continued trying the equilibrium approach, which recently has been intensively developed for improving resource management policies (Xu et all, 2018; Guo, 2018; James, 2017). With fining the subjects in such a way, the corresponding dyadic game has four equilibrium situations in pure strategies and five equilibrium situations in mixed strategies (Romanuke, 2010a). However, no one of these situations is simultaneously symmetric and profitable. An equilibrium situation at which the subjects work without treating wastewater (a symmetric situation) is totally senseless, because the subsequent fines in 3 units are far worse than just applying three water treatment systems. Another symmetric equilibrium situation is in mixed strategies, at which a cost for every environmental pollution subject is equal to $2-\sqrt{3} / 2$, i.e. this cost is about $13.4 \%$ higher than applying three water treatment 
systems. At this situation, about $21.13 \%$ of the water-for-manufacturing is discharged back into the reservoir without treatment. A promising situation, though neither equilibrium nor very profitable, is a case when only $5.9 \%$ of wastewater is not treated whereas it costs 0.971 units for every subject. Despite these costs are very close to costs for applying the water treatment system, there are no any other symmetric situation at which the costs would be less.

A generalization of fining was researched by Romanuke (2010b). The article considered the fine greater than the unit. If the fine is less than 2 units then the corresponding dyadic game does not have equilibrium situations. For the fine equal exactly 2 units, there is a single symmetric equilibrium situation at which every environmental pollution subject treats just a half of the discharged wastewater. Obviously, this situation is unprofitable as the reservoir is polluted irreversibly whereas it costs 1.5 units for every subject. For fines greater than 2 units, the game has a single symmetric equilibrium situation at which the cost for a subject decreases down to 1 unit as the fine increases. Theoretically, threat of heavy fines may force the environmental pollution subjects to totally convert their manufacturing to treating wastewater as every subject will pay 1 unit anyway. Although such "clean" situation is not a Nash equilibrium, its equilibration is forced by the threat of heavy fines. On the other hand, those heavy fines threaten with that some subjects may reduce their manufacturing because of the cost in 1 unit may be initially unprofitable or economically irrational.

\section{Goal of the article and tasks to be performed}

Inasmuch as heavy fines may ruin an economical balance among those three environmental pollution subjects and government, subsequently leading to cutting a budget for water resources conservation and recirculation, economically more reasonable fines should be substantiated. Thus, fining for when all subjects do not apply treatment must be heavier than fining when only two subjects do simultaneously not treat wastewater. Along with that, no less than two thirds of the polluted water is to be treated. To find a solution to such a problem, there are six tasks to be performed:

1. To state costs in the game explicitly.

2. To substantiate a range of the fine for when only two subjects do simultaneously not treat wastewater (let it be called a 2-fine).

3. To substantiate a range of the fine for when no one treats wastewater (let it be called a 3-fine).

4. In order to find an applicable solution, to sample the continuous set of situations in mixed strategies.

5. To find symmetric equilibria (over the sampled set), at which the cost for every subject is less than 1 unit.

6. For the found equilibria, to select those fines by which no less than two thirds of the polluted water is treated costing the least.

\section{Materials and methods}

\section{Costs of wastewater treatment in the dyadic 3-person game with generalized fines}

Denote a pure strategy of the $k$-th subject by $x_{k}$, where $x_{k} \in\{0,1\}$. Strategy $x_{k}=0$ implies that the $k$-th subject totally applies its water treatment system, whereas $x_{k}=1$ 
implies that all wastewater is discharged without treatment. Henceforward, a mixed strategy of the $k$-th subject can be represented as a probability $d_{k} \in[0 ; 1]$ of choosing pure strategy $x_{k}=1$. This is why strategies $x_{k}=1$ and $d_{k}=1$ coincide (implying the same action or decision), and strategies $x_{k}=0$ and $d_{k}=0$ coincide also.

There are eight situations in pure strategies written as $\left\{x_{1}, x_{2}, x_{3}\right\}$ in the dyadic 3-person game. A cost for the $k$-th subject in situation $\left\{x_{1}, x_{2}, x_{3}\right\}$ is $c_{k}\left(x_{1}, x_{2}, x_{3}\right)$ or, shortly, $c_{k}^{\left\langle x_{1} x_{2} x_{3}\right\rangle}$. If the 2-fine is $a$ and the 3 -fine is $b$, then (see the cube of situations and costs in Fig. 1):

$$
\begin{gathered}
c_{1}^{\langle 000\rangle}=c_{2}^{\langle 000\rangle}=c_{3}^{\langle 000\rangle}=1, \\
c_{1}^{\langle 010\rangle}=c_{3}^{\langle 010\rangle}=1, c_{2}^{\langle 010\rangle}=0, \\
c_{1}^{\langle 010\rangle}=c_{3}^{\langle 010\rangle}=1, c_{2}^{\langle 010\rangle}=0, \\
c_{2}^{\langle 100\rangle}=c_{3}^{\langle 100\rangle}=1, c_{1}^{\langle 100\rangle}=0, \\
c_{1}^{\langle 011\rangle}=1+a, c_{2}^{\langle 011\rangle}=c_{3}^{\langle 011\rangle}=a, \\
c_{2}^{\langle 101\rangle}=1+a, c_{1}^{\langle 101\rangle}=c_{3}^{\langle 101\rangle}=a, \\
c_{3}^{\langle 110\rangle}=1+a, c_{1}^{\langle 110\rangle}=c_{2}^{\langle 110\rangle}=a, \\
c_{1}^{\langle 111\rangle}=c_{2}^{\langle 111\rangle}=c_{3}^{\langle 111\rangle}=b .
\end{gathered}
$$

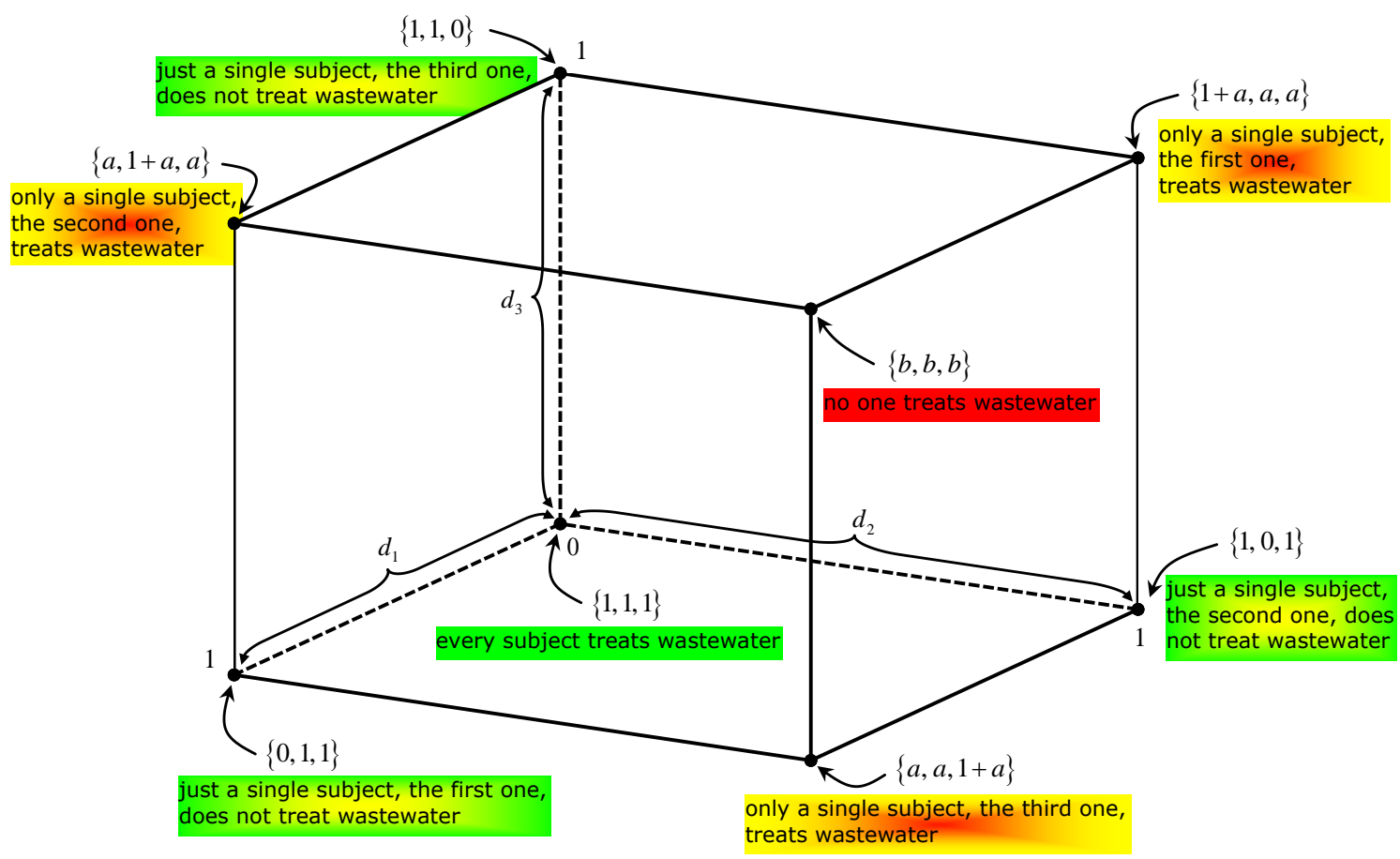

Figure 1. The cube of situations and costs in the dyadic 3-person game with generalized fines (see Romanuke, 2010b) 
A cost for the $k$-th subject in mixed strategies situation $\left\{d_{1}, d_{2}, d_{3}\right\}$ is:

$$
\begin{gathered}
c_{k}\left(d_{1}, d_{2}, d_{3}\right)= \\
=\left(1-d_{1}\right)\left(1-d_{2}\right)\left(1-d_{3}\right) c_{k}^{\langle 000\rangle}+ \\
+\left(1-d_{1}\right)\left(1-d_{2}\right) d_{3} c_{k}^{\langle 001\rangle}+ \\
+\left(1-d_{1}\right) d_{2}\left(1-d_{3}\right) c_{k}^{\langle 010\rangle}+ \\
+\left(1-d_{1}\right) d_{2} d_{3} c_{k}^{\langle 011\rangle}+ \\
+d_{1}\left(1-d_{2}\right)\left(1-d_{3}\right) c_{k}^{\langle 100\rangle}+ \\
+d_{1}\left(1-d_{2}\right) d_{3} c_{k}^{\langle 101\rangle}+ \\
+d_{1} d_{2}\left(1-d_{3}\right) c_{k}^{\langle 110\rangle}+ \\
+d_{1} d_{2} d_{3} c_{k}^{\langle 111\rangle}, k=\overline{1,3} .
\end{gathered}
$$

Plugging costs Equation 1 into Equation 2 gives:

$$
\begin{aligned}
& c_{1}\left(d_{1}, d_{2}, d_{3}\right)=1+a\left(d_{1} d_{2}+d_{2} d_{3}+d_{1} d_{3}\right)+(b-3 a) d_{1} d_{2} d_{3}-d_{1}, \\
& c_{2}\left(d_{1}, d_{2}, d_{3}\right)=1+a\left(d_{1} d_{2}+d_{2} d_{3}+d_{1} d_{3}\right)+(b-3 a) d_{1} d_{2} d_{3}-d_{2}, \\
& c_{3}\left(d_{1}, d_{2}, d_{3}\right)=1+a\left(d_{1} d_{2}+d_{2} d_{3}+d_{1} d_{3}\right)+(b-3 a) d_{1} d_{2} d_{3}-d_{3} .
\end{aligned}
$$

Every subject struggles to minimize its cost by adjusting the probability of discharging without treatment. If in situation $\left\{d_{1}^{*}, d_{2}^{*}, d_{3}^{*}\right\}$ costs $(E q s .3-5)$ are such that

$$
\begin{aligned}
& c_{1}\left(d_{1}^{*}, d_{2}, d_{3}\right) \leqslant c_{1}\left(d_{1}, d_{2}, d_{3}\right) \text { by } d_{k} \in[0 ; 1] \forall k=\overline{1,3}, \\
& c_{2}\left(d_{1}, d_{2}^{*}, d_{3}\right) \leqslant c_{2}\left(d_{1}, d_{2}, d_{3}\right) \text { by } d_{k} \in[0 ; 1] \forall k=\overline{1,3}, \\
& c_{3}\left(d_{1}, d_{2}, d_{3}^{*}\right) \leqslant c_{3}\left(d_{1}, d_{2}, d_{3}\right) \text { by } d_{k} \in[0 ; 1] \forall k=\overline{1,3},
\end{aligned}
$$

then situation $\left\{d_{1}^{*}, d_{2}^{*}, d_{3}^{*}\right\}$ is an equilibrium (by Nash). The equilibrium situation is explicitly determined by inequalities (Eqs. 6-8) represented in the form of inequalities

$$
\begin{gathered}
1+a\left(d_{1}^{*} d_{2}+d_{2} d_{3}+d_{1}^{*} d_{3}\right)+(b-3 a) d_{1}^{*} d_{2} d_{3}-d_{1}^{*} \leqslant \\
\leqslant 1+a\left(d_{1} d_{2}+d_{2} d_{3}+d_{1} d_{3}\right)+(b-3 a) d_{1} d_{2} d_{3}-d_{1} \text { by } d_{k} \in[0 ; 1] \forall k=\overline{1,3}, \\
1+a\left(d_{1} d_{2}^{*}+d_{2}^{*} d_{3}+d_{1} d_{3}\right)+(b-3 a) d_{1} d_{2}^{*} d_{3}-d_{2}^{*} \leqslant \\
\leqslant 1+a\left(d_{1} d_{2}+d_{2} d_{3}+d_{1} d_{3}\right)+(b-3 a) d_{1} d_{2} d_{3}-d_{2} \text { by } d_{k} \in[0 ; 1] \forall k=\overline{1,3},
\end{gathered}
$$




$$
\begin{gathered}
1+a\left(d_{1} d_{2}+d_{2} d_{3}^{*}+d_{1} d_{3}^{*}\right)+(b-3 a) d_{1} d_{2} d_{3}^{*}-d_{3}^{*} \leqslant \\
\leqslant 1+a\left(d_{1} d_{2}+d_{2} d_{3}+d_{1} d_{3}\right)+(b-3 a) d_{1} d_{2} d_{3}-d_{3} \text { by } d_{k} \in[0 ; 1] \forall k=\overline{1,3} .
\end{gathered}
$$

Inequalities (Eq. 9-11) are subsequently simplified:

$$
\begin{gathered}
d_{1}^{*}\left(a\left(d_{2}+d_{3}\right)+(b-3 a) d_{2} d_{3}-1\right) \leqslant \\
\leqslant d_{1}\left(a\left(d_{2}+d_{3}\right)+(b-3 a) d_{2} d_{3}-1\right) \text { by } d_{k} \in[0 ; 1] \forall k=\overline{1,3}, \\
d_{2}^{*}\left(a\left(d_{1}+d_{3}\right)+(b-3 a) d_{1} d_{3}-1\right) \leqslant \\
\leqslant d_{2}\left(a\left(d_{1}+d_{3}\right)+(b-3 a) d_{1} d_{3}-1\right) \text { by } d_{k} \in[0 ; 1] \forall k=\overline{1,3}, \\
d_{3}^{*}\left(a\left(d_{1}+d_{2}\right)+(b-3 a) d_{1} d_{2}-1\right) \leqslant \\
\leqslant d_{3}\left(a\left(d_{1}+d_{2}\right)+(b-3 a) d_{1} d_{2}-1\right) \text { by } d_{k} \in[0 ; 1] \forall k=\overline{1,3} .
\end{gathered}
$$

So, a situation with probabilities $d_{1}^{*}, d_{2}^{*}, d_{3}^{*}$ becomes a Nash equilibrium if inequalities (Eqs. 12-14) hold. In such a situation, an environmental pollution subject cannot pay less acting on its own. If two or three subjects start searching for decreasing their costs, the equilibrium is ruined as subsequent costs for at least one party will be greater than previously. Obviously, equilibration is strongly dependent on what 2-fine and 3-fine are and how much they differ. The best situation is such that

$$
d_{1}^{*}=d_{2}^{*}=d_{3}^{*}=d^{*} \leqslant 1 / 3
$$

for the stated problem.

\section{A range of the 2-fine}

The model claims that the polluted water recovers without treating it by investing 2 units. This is a situation when two of three environmental pollution subjects apply their water treatment systems. When only a single subject applies, a unit is lacked. Measurement of a water pollution rate cannot reveal which subject is "clean" and which subjects work "polluted". Therefore, every subject is fined. The sum of three 2 -fines should be equal to 1 unit or greater. So, a minimally possible 2 -fine is one third of the unit.

Now, a maximal 2-fine should be considered. As it is mentioned above, setting $a>1$ is unfavorable. In the case of $a=1$ or close to that, the "clean" subject potentially pays a doubled cost. This is a kind of demotivation for conscientious subjects. Besides, this may be a (negative) motivation for violators. The case of $a=0.75$ is more attractive but nonetheless the "clean" subject may eventually pay too much. In the case of $a=0.5$ the investment into the reservoir is 2.5 units, which is sufficient for maintaining the ecologically healthy water balance. Hence, the 2-fine can be studied within range $[0.34 ; 0.5]$ by a step of 0.01 (instead of unsuitable 0.33 , the marginal endpoint 0.34 is included for closing the range). However, if no solution is found, the range must be widened. 


\section{A range of the 3-fine}

When no one treats wastewater, the sum of 3 -fines should be far greater than that $(2$ units), which is sufficient for the ecologically healthy water balance. A reason is that worse pollution may require more investment for recovering. This is so because of a water recover function is probably not linear. Another reason is to demotivate violators. Such demotivation must be stronger than a minimal 2-fine. Hence, a suitable range for the 3-fine is from $a$ up to $5 a$. The step can be set at $a / 10$, rougher than for the 2 -fine as the latter is more influential. Note that such a range implies inequality $b \geqslant a$ although inequality $b \leqslant 1+a$ is possible. This means that the case with the totally senseless equilibrium of a situation, when no one treats wastewater, here is not excluded.

\section{Sampling the continuous set of situations in mixed strategies}

It is apparent that the dyadic 3-person game (see Fig. 1), by fixing some $a$ and $b$ from their ranges, will not have profitable symmetric equilibria in pure strategies. So, the best solution will be sought in mixed strategies. But, even if a profitable symmetric equilibrium in mixed strategies exists, it is likely to contain probabilities which are either irrational numbers or irreducible fractions with great denominators. Practical realization of such probabilities is impossible: relative frequencies (of both pure strategies) tend to be represented as much simpler fractions like $1 / 2, n / 3$ by $n \in\{1,2\}, n / 4$ by $n \in\{\overline{1,3}\}$, and so on, because switches from "clean" to "polluting" manufacturing and backwards cannot be too frequent. An exception could be if the work of those environmental pollution subjects was observed and controlled for a few years without any corrections by inflation, development, implementation of new technologies, etc. In other words, such exception is hardly plausible.

Therefore, the continuous set of situations in mixed strategies is sampled to obtain a finite lattice of situations. The lattice is

$$
\mathscr{L}=\chi_{k=1}^{3}\left\{d_{k}^{\langle j\rangle}\right\}_{j=0}^{M} \text { by } M \in \mathbb{N} \backslash\{1\},
$$

where $d_{k}^{\langle j\rangle}=j / M$ is a mixed strategy (being factually a probability) of the $k$-th subject. Lattice (Eq. 16) is regular as its step $1 / M$ is a constant (Fig. 2).

Nevertheless, the game may not have a symmetric profitable equilibrium even over the sampled set of situations in mixed strategies. Thus, concessions in costs will be considered.

\section{Results}

\section{Approximate equilibria by cost concessions}

When an exact equilibrium does not exist, or condition (Eq. 15) does not hold, an approximate equilibrium is found by a concession $\beta$ (for more detailed analysis, see it in Romanuke, 2016). Instead of inequalities (Eq. 12-14), if inequalities

$$
\begin{gathered}
d_{1}^{\langle\beta\rangle}\left(a\left(d_{2}+d_{3}\right)+(b-3 a) d_{2} d_{3}-1\right)-\beta \leqslant \\
\leqslant d_{1}\left(a\left(d_{2}+d_{3}\right)+(b-3 a) d_{2} d_{3}-1\right) \text { by } d_{k} \in[0 ; 1] \forall k=\overline{1,3},
\end{gathered}
$$




$$
\begin{gathered}
d_{2}^{\langle\beta\rangle}\left(a\left(d_{1}+d_{3}\right)+(b-3 a) d_{1} d_{3}-1\right)-\beta \leqslant \\
\leqslant d_{2}\left(a\left(d_{1}+d_{3}\right)+(b-3 a) d_{1} d_{3}-1\right) \text { by } d_{k} \in[0 ; 1] \forall k=\overline{1,3}, \\
d_{3}^{\langle\beta\rangle}\left(a\left(d_{1}+d_{2}\right)+(b-3 a) d_{1} d_{2}-1\right)-\beta \leqslant \\
\leqslant d_{3}\left(a\left(d_{1}+d_{2}\right)+(b-3 a) d_{1} d_{2}-1\right) \text { by } d_{k} \in[0 ; 1] \forall k=\overline{1,3}
\end{gathered}
$$

hold for some $\beta>0$, then $\left\{d_{1}^{\langle\beta\rangle}, d_{2}^{\langle\beta\rangle}, d_{3}^{\langle\beta\rangle}\right\}$ is the approximate equilibrium. The concession is a kind of re-achieving an equilibrium at a situation by small losses when the situation is not in equilibrium (by Nash). By an appropriate concession $\beta$, condition

$$
d_{1}^{\langle\beta\rangle}=d_{2}^{\langle\beta\rangle}=d_{3}^{\langle\beta\rangle}=d^{\langle\beta\rangle} \leqslant 1 / 3
$$

defines the best approximate equilibrium. Clearly, the greater the concession is, the less stable the respective approximate equilibrium becomes.

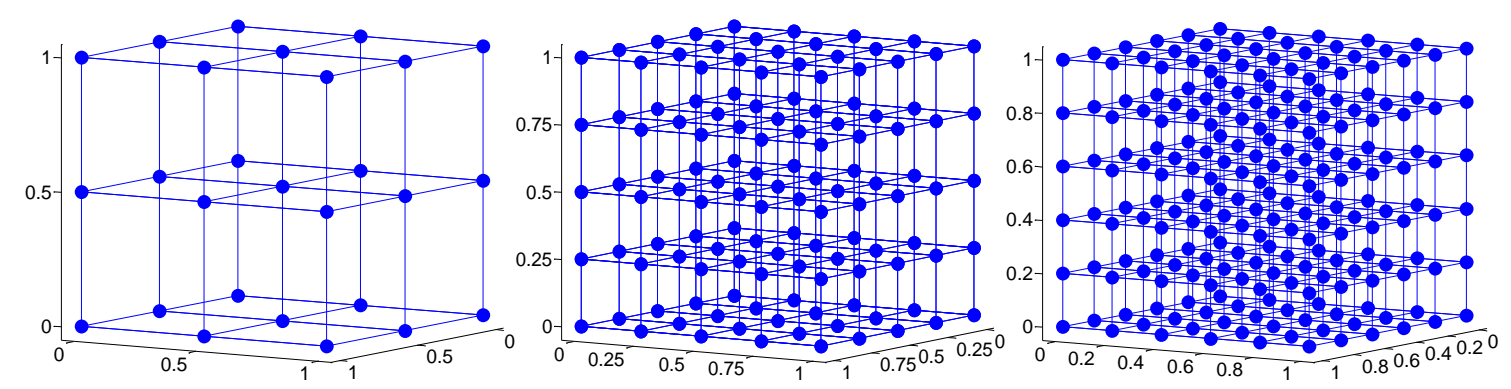

Figure 2. The regular finite lattice of situations in the dyadic 3-person game by decreasing the sampling step (from the left to the right)

In the game being considered, an initial concession can be set at between 0.01 and 0.11 with a step of 0.01 (the marginal endpoint 0.11 is included for closing the range). However, condition (Eq. 17) does not hold for $\beta \in[0.01 ; 0.11]$ (see it by 2-fines along with concessions in Fig. 3 and by 3 -fines along with costs in Fig. 4). Subsequently, let the range of 2 -fines be widened to $[0.34 ; 1]$ and the range of concessions be widened to $[0.01 ; 0.5]$. For these widened ranges, condition (Eq. 17) holds for $\beta \geqslant 0.21$ (Fig. 5), but sampling with a step of $1 / 16$ is canceled as it is practically unrealizable (although it is promising in bringing minimal and maximal fines, costs, and concessions closer).

The symmetric "cleanest" situation (see it in Fig. 5 at $M=9$ )

$$
\left\{d_{1}^{\langle 0.5\rangle}, d_{2}^{\langle 0.5\rangle}, d_{3}^{\langle 0.5\rangle}\right\}=\{1 / 9,1 / 9,1 / 9\}
$$

has pretty narrow gaps for 2-fines and costs (Fig. 6). The corresponding gap for 3-fines is the narrowest (Fig. 7). Nonetheless, situation (Eq. 18) considered as an approximate equilibrium is risky to be too unstable because of very great concessions (which are greater than maximal 2-fines). This is why situation ( $E q .18)$ is excluded from further consideration. On the other hand, this sampling has another two, less "clean", situations 


$$
\left\{d_{1}^{\langle\beta\rangle}, d_{2}^{\langle\beta\rangle}, d_{3}^{\langle\beta\rangle}\right\}=\{2 / 9,2 / 9,2 / 9\}
$$

and

$$
\left\{d_{1}^{\langle\beta\rangle}, d_{2}^{\langle\beta\rangle}, d_{3}^{\langle\beta\rangle}\right\}=\{1 / 3,1 / 3,1 / 3\}
$$

which satisfy condition (Eq. 17). The concession for approximate equilibrium

$$
\left\{d_{1}^{\langle 0.19\rangle}, d_{2}^{\langle 0.19\rangle}, d_{3}^{\langle 0.19\rangle}\right\}=\{1 / 3,1 / 3,1 / 3\}
$$

is just 0.19 , but the costs are higher than 0.9966 units.

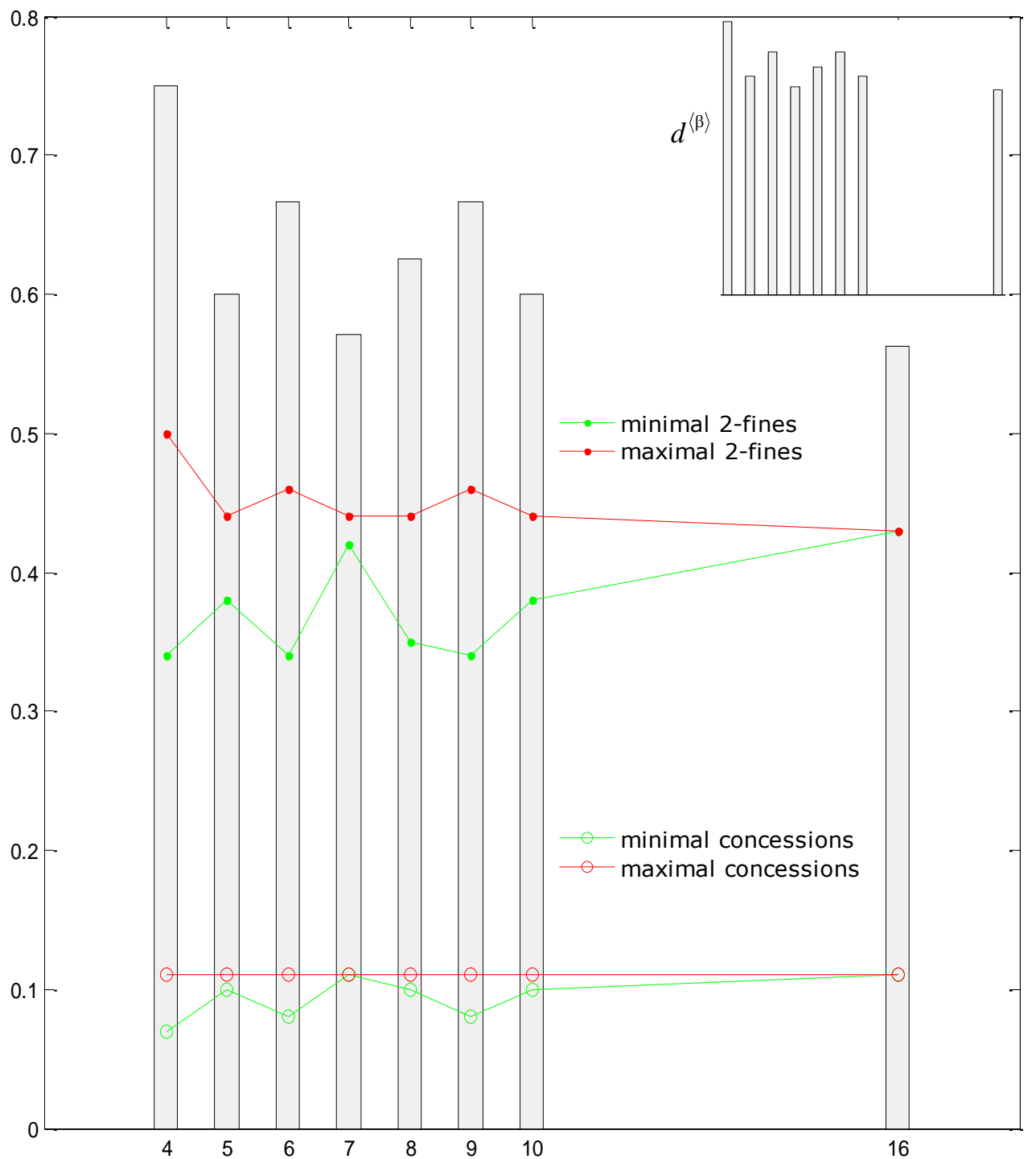

Figure 3. The slowly decreasing minimal probability of discharging without treatment by the corresponding gap of 2-fines along with the corresponding gap of concessions for $\beta \in[0.01 ; 0.11]$ and $a \in[0.34 ; 0.5]$ 


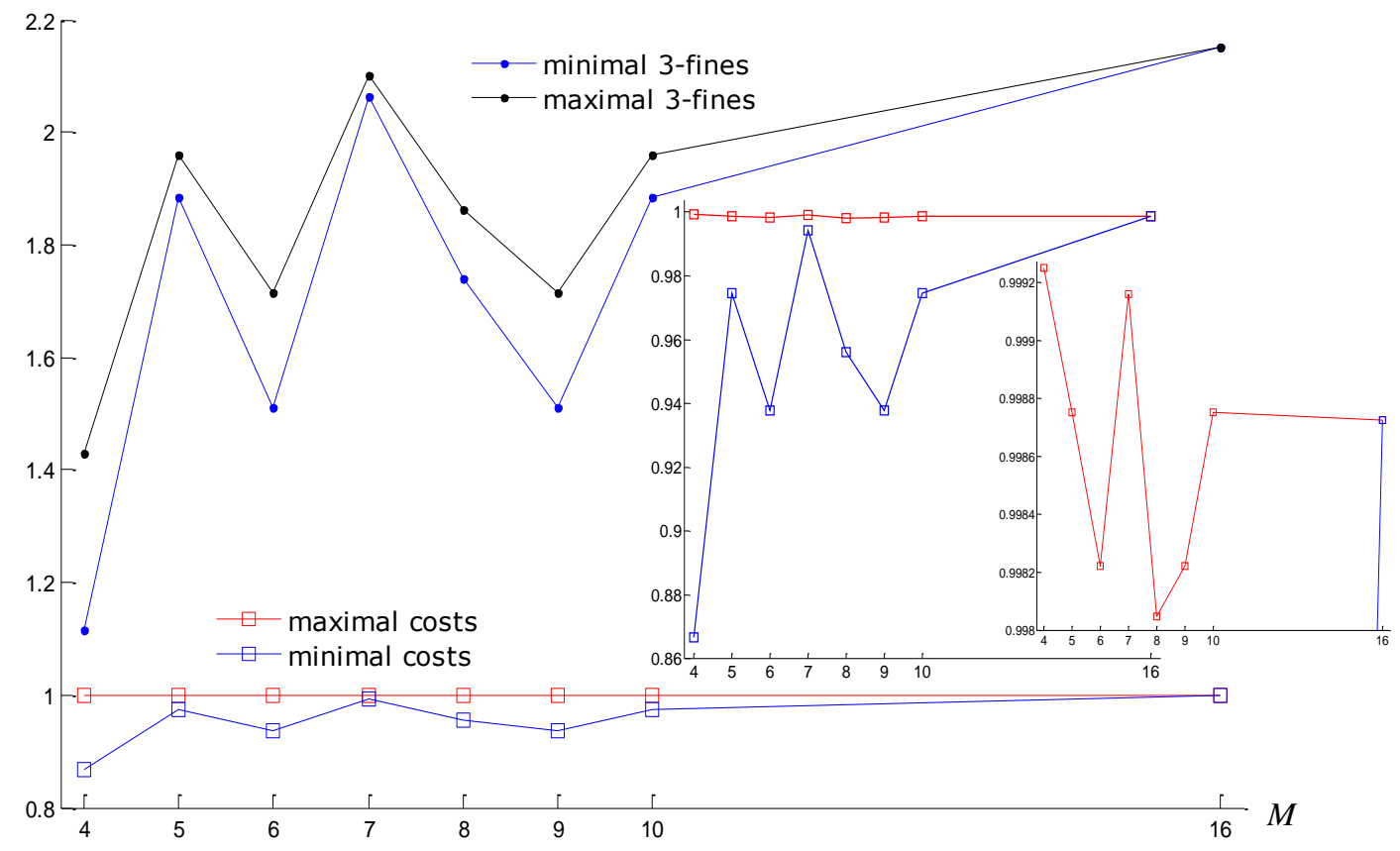

Figure 4. The corresponding gap of increasing 3-fines along with the corresponding gap of costs (which, nonetheless, all are acceptable) for $\beta \in[0.01 ; 0.11]$ and $a \in[0.34 ; 0.5]$

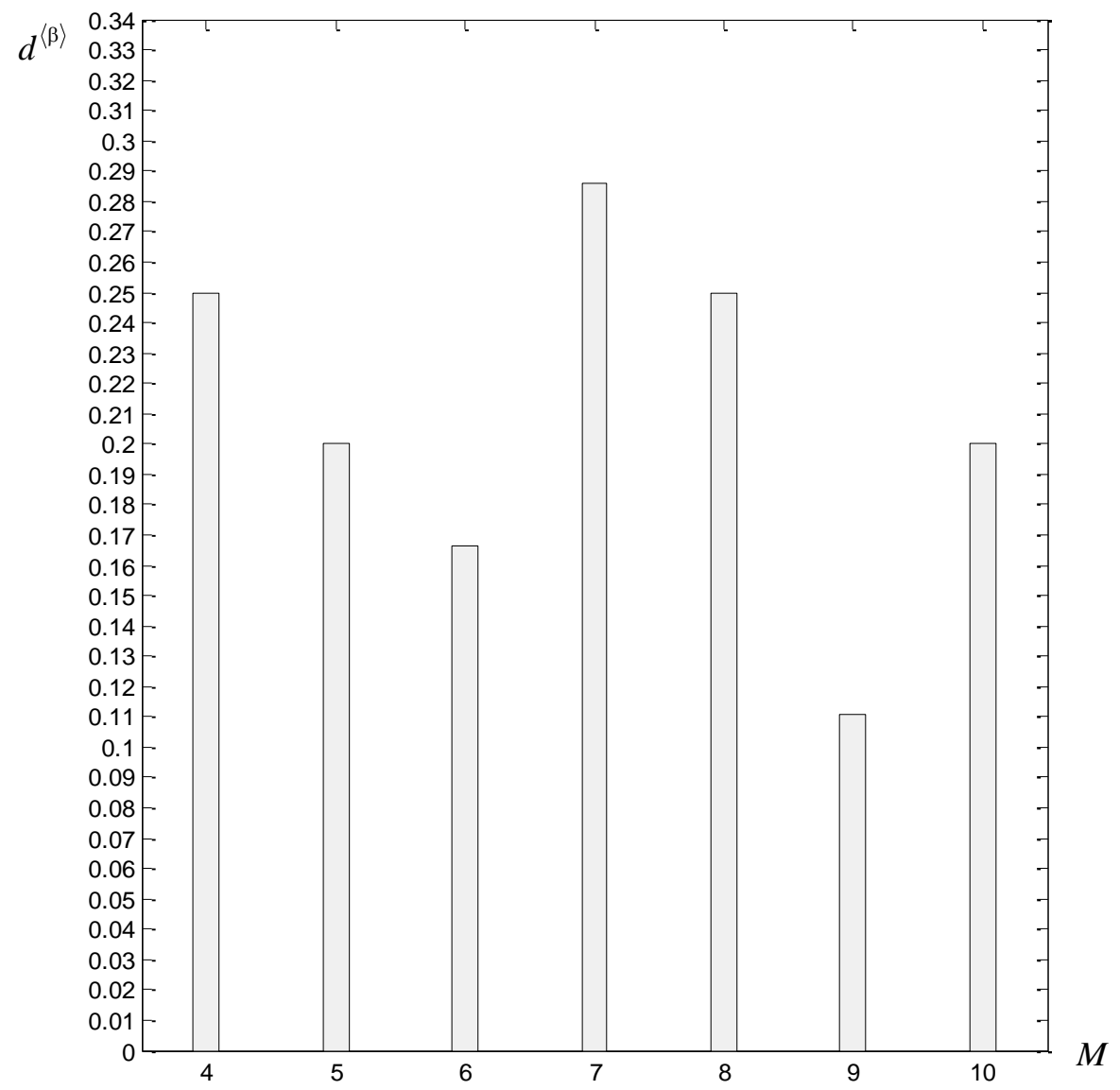

Figure 5. The minimal probability of discharging without treatment for $\beta \in[0.01 ; 0.5]$ and $a \in[0.34 ; 1]$, at which the ecologically healthy water balance of the reservoir is maintained owing to recovering 


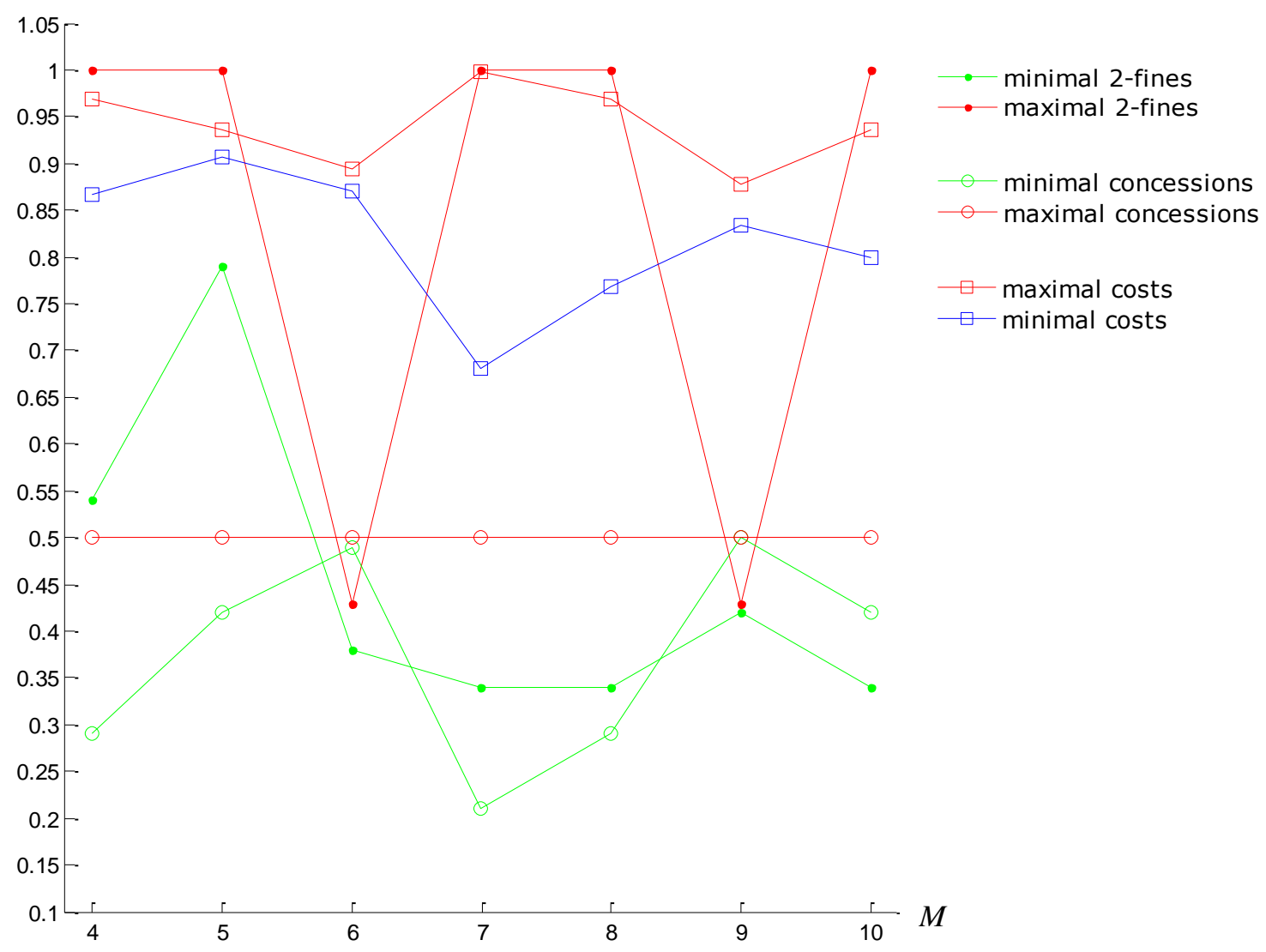

Figure 6. The corresponding gaps of 2-fines, concessions, and costs for $\beta \in[0.01 ; 0.5]$ and $a \in[0.34 ; 1]$, at which the ecologically healthy water balance of the reservoir is maintained owing to recovering

Sampling with a step of $1 / 4$ has wider gaps than those for $M=5$. In its turn, sampling with a step of $1 / 5$ has wider gaps than those for $M=6$. The widest gaps are at $M=7$ but approximate equilibria

$$
\left\{d_{1}^{\langle\beta\rangle}, d_{2}^{\langle\beta\rangle}, d_{3}^{\langle\beta\rangle}\right\}=\{2 / 7,2 / 7,2 / 7\}
$$

by such sampling are achieved by

$$
\begin{gathered}
0.21 \leqslant \beta \leqslant 0.5, \\
0.34 \leqslant a \leqslant 1,
\end{gathered}
$$

and

$$
0.62 \leqslant b \leqslant 4.85
$$

which are very promising. In fact, situation (Eq. 21) is achievable at the smallest concession $\beta=0.21$ (see the minimum in Fig. 6).

Despite "clean" situation (Eq. 21) implies the heaviest discharge without treatment, it is the most stable approximate equilibrium owing to the smallest concession. Thus, approximate equilibrium 


$$
\left\{d_{1}^{\langle 0.21\rangle}, d_{2}^{\langle 0.21\rangle}, d_{3}^{\langle 0.21\rangle}\right\}=\{2 / 7,2 / 7,2 / 7\}
$$

is exactly achieved at $a=0.97$ and $b=4.85$. Eventually, however, situation (Eq. 22) forces every environmental pollution subject to pay about 0.9971 units. That makes this situation almost senseless under those fines. Besides, those fines are heavy and they seem discouraging.

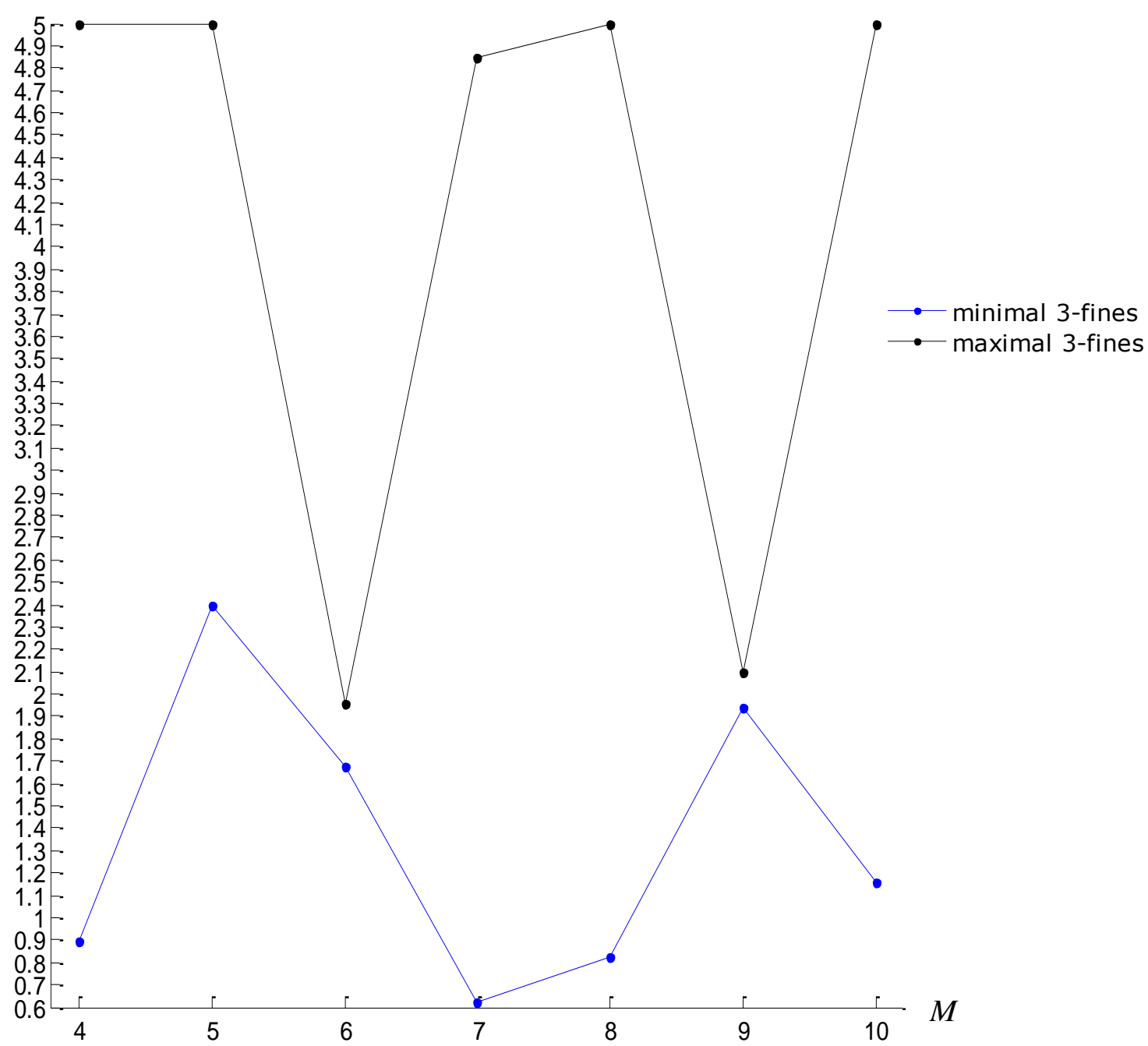

Figure 7. The corresponding gaps of 3-fines for $\beta \in[0.01 ; 0.5]$ and $a \in[0.34 ; 1]$, at which the ecologically healthy water balance of the reservoir is maintained owing to recovering

Approximate equilibrium

$$
\left\{d_{1}^{\langle 0.29\rangle}, d_{2}^{\langle 0.29\rangle}, d_{3}^{\langle 0.29\rangle}\right\}=\{1 / 4,1 / 4,1 / 4\}
$$

exactly achieved at $a=0.99$ and $b=4.95$ is rejected by similar reasoning: every subject will eventually pay 0.9666 units. Another relatively acceptable concession, possible at $M=8$, does not seem better: approximate equilibrium 


$$
\left\{d_{1}^{\langle 0.29\rangle}, d_{2}^{\langle 0.29\rangle}, d_{3}^{\langle 0.29\rangle}\right\}=\{1 / 8,1 / 8,1 / 8\}
$$

is achieved at the same fines (plausibly, due to the doubled sampling) forcing the same cost. Meanwhile, a hardly acceptable concession, possible at $M=6$, allows to achieve approximate equilibrium

$$
\left\{d_{1}^{\langle 0.49\rangle}, d_{2}^{\langle 0.49\rangle}, d_{3}^{\langle 0.49\rangle}\right\}=\{1 / 6,1 / 6,1 / 6\}
$$

at $a=0.4$ and $b=1.92$, being quite acceptable fines, which costs only 0.89 units. Another dubious concession, possible at $M=10$, will cost 0.8227 units if the subjects hold at approximate equilibrium

$$
\left\{d_{1}^{\langle 0.42\rangle}, d_{2}^{\langle 0.42\rangle}, d_{3}^{\langle 0.42\rangle}\right\}=\{1 / 5,1 / 5,1 / 5\}
$$

by $a=0.4$ and $b=1.68$ (even more acceptable 3-fines for the subjects). Samplings at $M=6$ and $M=10$ have their second possible approximate equilibria: less "clean" situation (Eq. 19) at $M=6$ and

$$
\left\{d_{1}^{\langle\beta\rangle}, d_{2}^{\langle\beta\rangle}, d_{3}^{\langle\beta\rangle}\right\}=\{3 / 10,3 / 10,3 / 10\}
$$

at $M=10$. And again, the relatively small concession in approximate equilibrium (Eq. 20) stands against the same high cost as it has been in the case of $M=9$. A relative stability of approximate equilibrium

$$
\left\{d_{1}^{\langle 0.2\rangle}, d_{2}^{\langle 0.2\rangle}, d_{3}^{\langle 0.2\rangle}\right\}=\{3 / 10,3 / 10,3 / 10\}
$$

at $M=10$ is expensive: the costs are higher than 0.998 units.

So, it is apparent that struggling to minimize concessions within those gaps in Figure 6 leads to increasing costs. Apart from democratizing fines, the next stage is to balance costs with concessions, starting off minimal concessions for each $M=\overline{4,10}$. At that, concessions close to 0.5 (see Fig. 6) are unacceptable. For example, both approximate equilibria (Eq. 23) and (Eq. 24) are unstable, losing thus their practicability (in spite of their lower costs compared to more stable approximate equilibria).

\section{Fines producing symmetric "clean" situations whose costs are the least}

Henceforward, both costs and concessions are to be minimized. In order to do this, denote by $\gamma_{i}(M)$ the subject's cost at the $i$-th set of fines

$$
\left\{a_{i}(M), b_{i}(M)\right\}
$$

and the concession 


$$
\beta_{i}(M) \text { for } M=\overline{4,10} \text { and } i=\overline{1, I_{M}}
$$

for $I_{M}$ sequences

$$
\left\{\gamma_{i}(M), \beta_{i}(M), a_{i}(M), b_{i}(M)\right\}_{i=1}^{I_{M}}
$$

at which $\gamma_{i}(M)<1$ and condition (Eq. 17) holds, i.e.

$$
d_{1}^{\left\langle\beta_{i}(M)\right\rangle}=d_{2}^{\left\langle\beta_{i}(M)\right\rangle}=d_{3}^{\left\langle\beta_{i}(M)\right\rangle}=d^{\left\langle\beta_{i}(M)\right\rangle} \leqslant 1 / 3 .
$$

Having

$$
\gamma_{\min }(M)=\min _{i=1, I_{M}} \gamma_{i}(M)
$$

and

$$
\beta_{\min }(M)=\min _{i=1, I_{M}} \beta_{i}(M),
$$

the best couple of the cost and concession can be found by its index

$$
i^{*} \in \arg \min _{i=1, I_{M}} \sqrt{\left(\gamma_{i}(M)-\gamma_{\min }(M)\right)^{2}+\left(\beta_{i}(M)-\beta_{\min }(M)\right)^{2}}
$$

for the given $M$. With distance

$$
\rho_{i}(M)=\sqrt{\left(\gamma_{i}(M)-\gamma_{\text {min }}(M)\right)^{2}+\left(\beta_{i}(M)-\beta_{\text {min }}(M)\right)^{2}}
$$

used in (Eq. 25), it is admissible to loose its minimum by $2 \%$. Thus, a set of indices

$$
L_{*}(M)=\left\{i \in\left\{\overline{1, I_{M}}\right\}: \rho_{i}(M) \leqslant 1.02 \cdot \rho_{i}(M)\right\} \subset\left\{\overline{1, I_{M}}\right\}
$$

will give the best couples

$$
\left\{\gamma_{i^{*}}^{* *}(M), \beta_{i^{* *}}^{*}(M)\right\}_{i^{*}=1}^{\left|L_{*}(M)\right|} \subset\left\{\left\{\gamma_{i}(M), \beta_{i}(M)\right\}_{i=1}^{I_{M}}\right\}_{M=4}^{10}
$$

for the given $M$, where the superscript asterisk refers to re-indexation started from 1 again in the subscript. Couples 


$$
\left\{\left\{\gamma_{i}(M), \beta_{i}(M)\right\}_{i=1}^{I_{M}}\right\}_{M=4}^{10}
$$

are specifically shown in Figures $8-14$, where thicker dots correspond to lower 2-fines, black dots correspond to that $b_{i}(M)<2$, light dots correspond to that $b_{i}(M) \geqslant 3.5$, and dots are moderately darkened if

$$
2 \leqslant b_{i}(M)<3.5
$$

Lines in those graphs link best couples (Eq. 27) to couple (drawn as a circled dot)

$$
\left\{\gamma_{\min }(M), \beta_{\min }(M)\right\}
$$

for every $M=\overline{4,10}$. The thickest line in every graph links couple (Eq. 28) to couple

$$
\left\{\gamma_{i^{*}}(M), \beta_{i^{*}}(M)\right\} \in\left\{\gamma_{i^{* *}}^{*}(M), \beta_{i^{* *}}^{*}(M)\right\}_{i^{* *}=1}^{\left|L_{i}(M)\right|}
$$

for the given $M$, which is the shortest in the graph.

Further below is a table (Table 1) with a list of subsets

$$
\begin{gathered}
\left\{\left\{\gamma_{i^{* *}}^{*}(M), \beta_{i^{* *}}^{*}(M), a_{i^{* *}}^{*}(M), b_{i^{* *}}^{*}(M)\right\}_{i^{* *}=1}^{L_{(}(M) \mid} \subset\right. \\
\left.\subset\left\{\gamma_{i}(M), \beta_{i}(M), a_{i}(M), b_{i}(M)\right\}_{i=1}^{I_{M}}\right\}_{M=4}^{10}
\end{gathered}
$$

along with distances

$$
\left\{\left\{\rho_{i^{* * *}}^{*}(M)\right\}_{i^{* * *}=1}^{\left|L_{*}(M)\right|}\right\}_{M=4}^{10}
$$

by (Eq. 26), where the superscript asterisk refers to re-indexation started from 1 again in the subscript. Note that any two distances for different samplings are incomparable due couple (Eq. 28) changes as $M$ increases (that is, sampling becomes more compact). Therefore, a generalized distance is introduced to a couple of the minimal cost

$$
\gamma_{\min }^{*}=\min _{M=4,10}\left(\min _{i=1, I_{M}} \gamma_{i}(M)\right) \approx 0.6042
$$

and the minimal concession

$$
\beta_{\min }^{*}=\min _{M=4,10}\left(\min _{i=1, I_{M}} \beta_{i}(M)\right)=0.19
$$




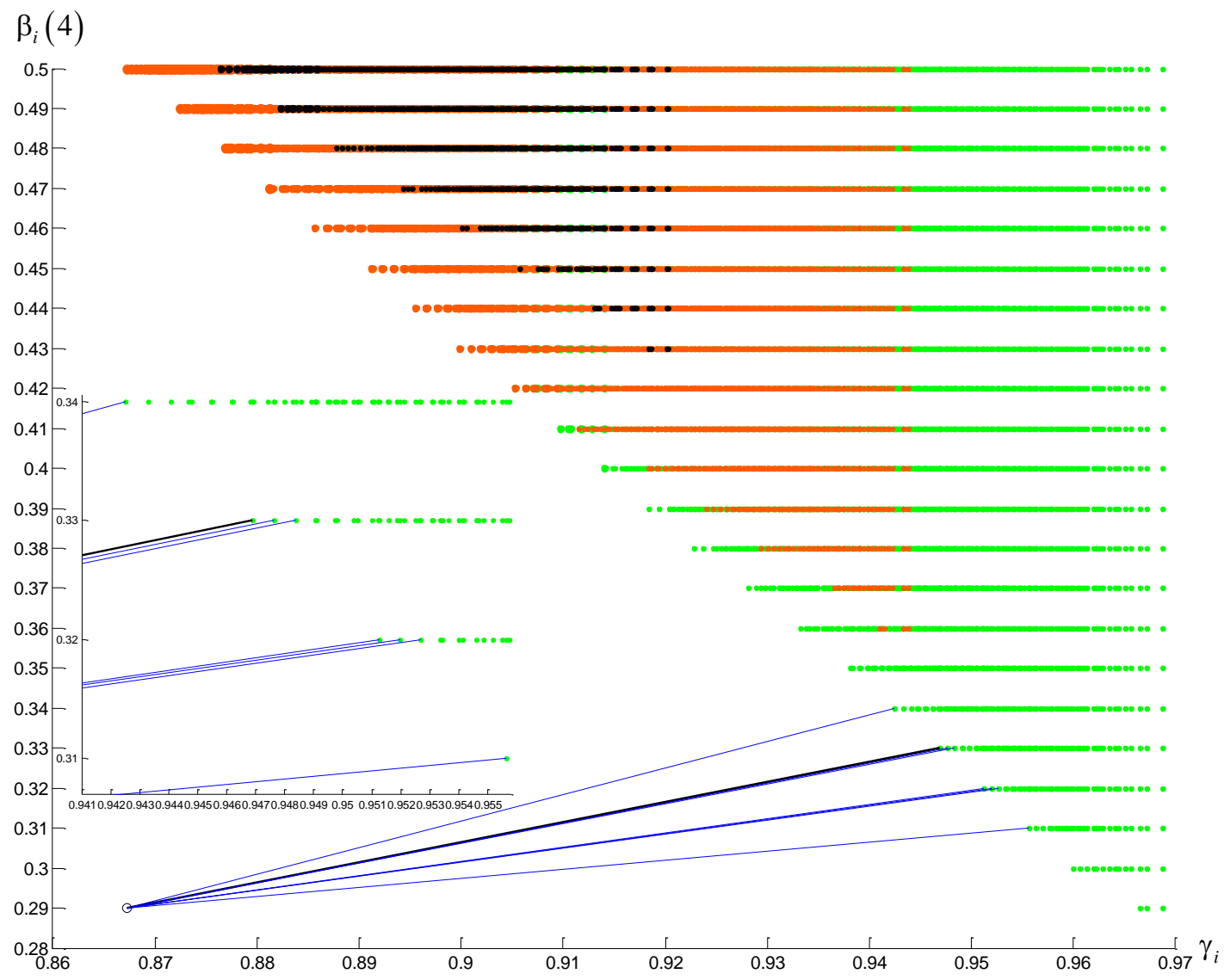

Figure 8. The loosest sampling has 8 versions of best couples (Eq. 27) having concessions up to 0.34

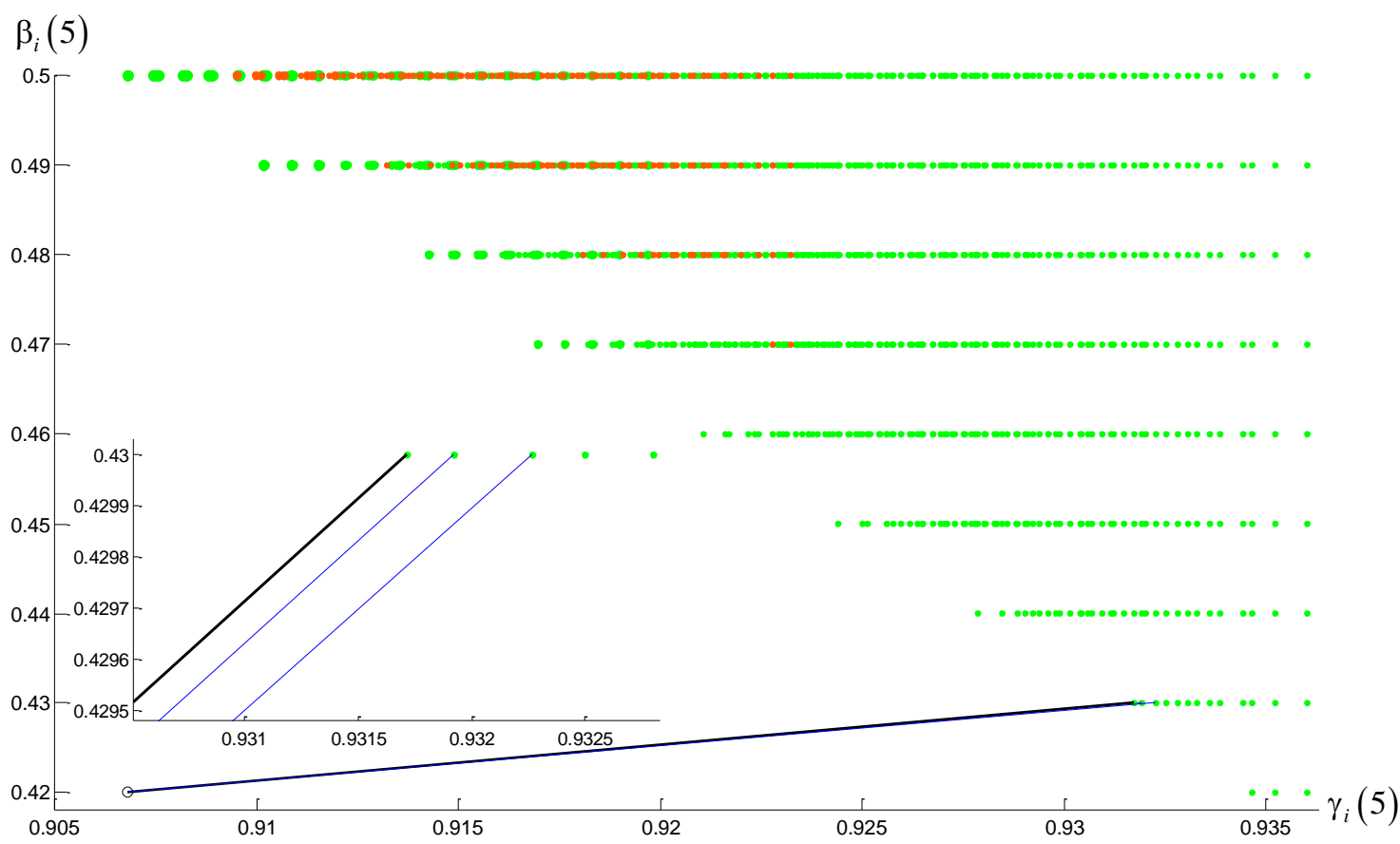

Figure 9. Another 3 versions of best couples (Eq. 27) but the concession here is too great (and so are 3-fines throughout this sampling) 


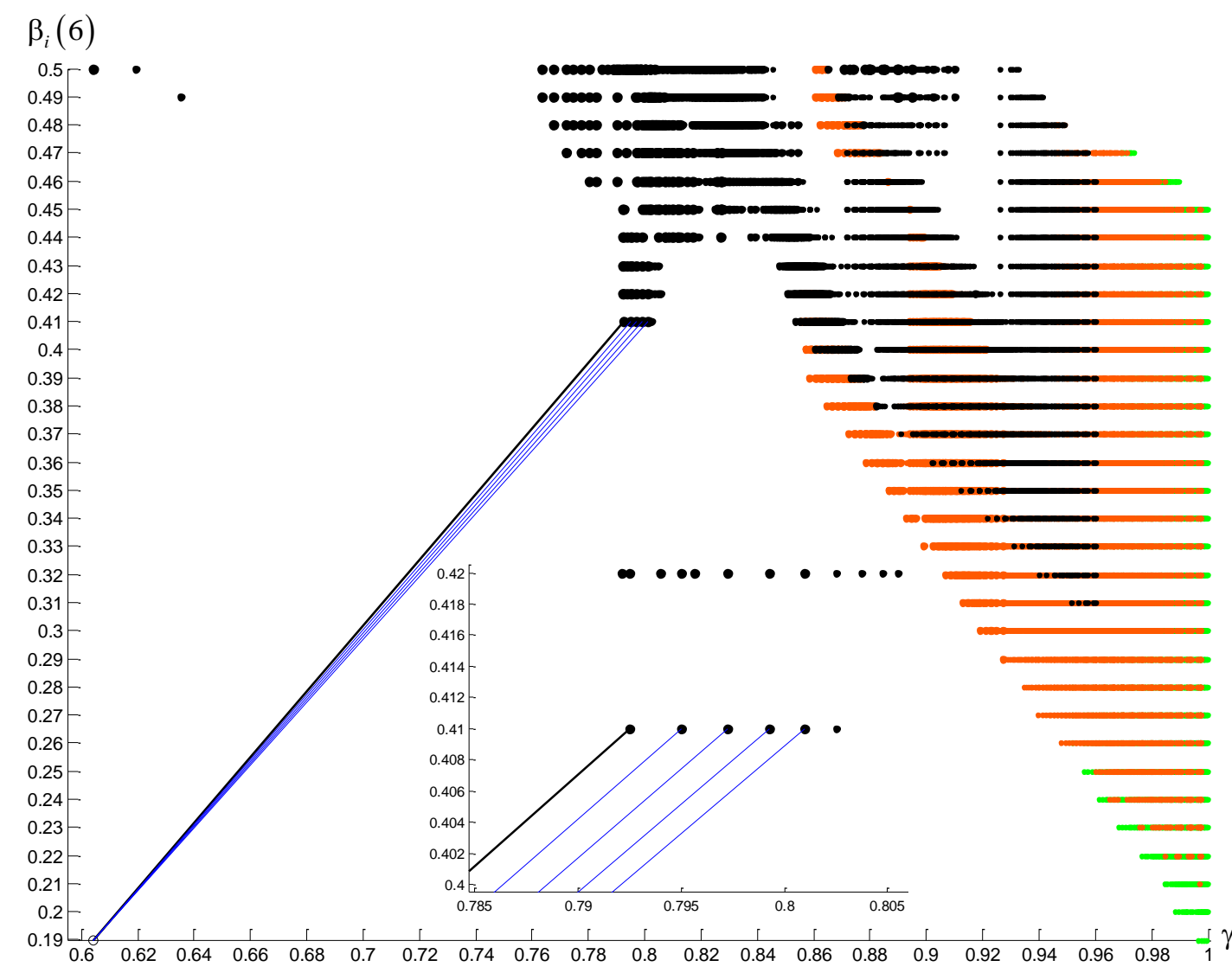

Figure 10. Great concessions but acceptable costs in these 5 versions of best couples (Eq. 27); the corresponding fines are light

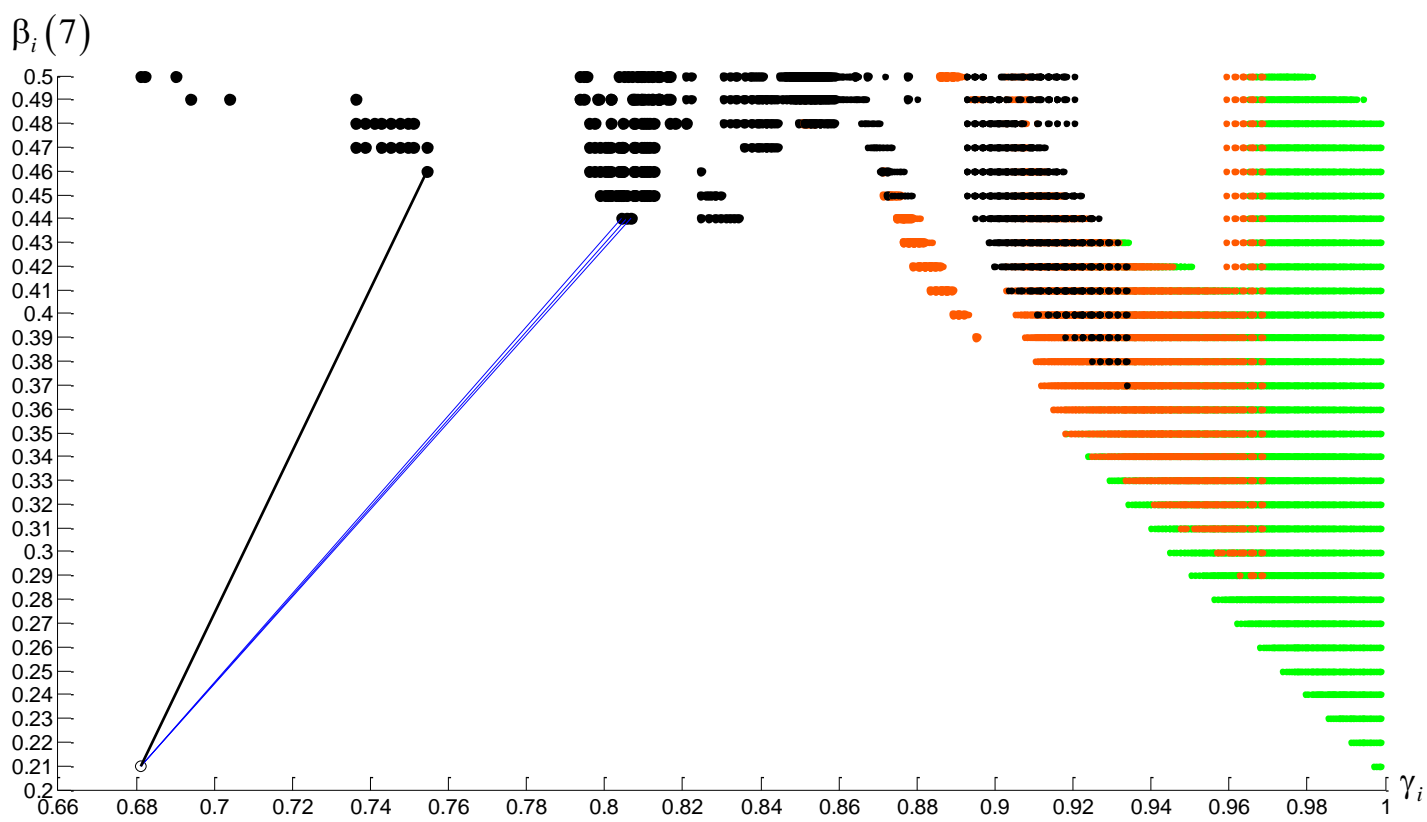

Figure 11. Great concessions but acceptable costs, especially for couple (Eq. 29), in these 4 versions of best couples (Eq. 27); the corresponding fines are light 


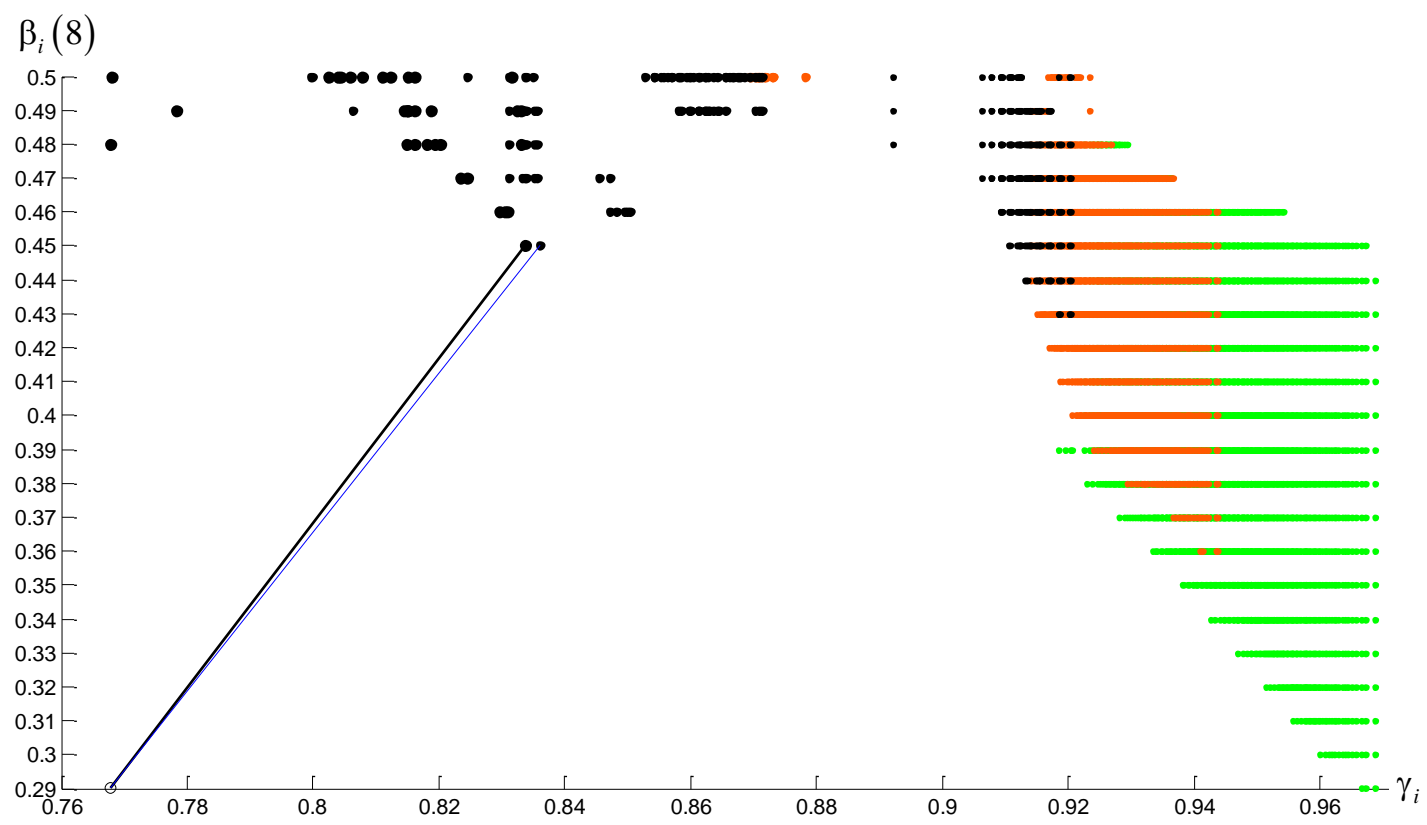

Figure 12. After the doubled initial sampling, here are only 2 versions of best couples (Eq. 27) including couple (Eq. 29) by unacceptable concessions; now the corresponding fines are a little bit heavier than in Figures 10 and 11

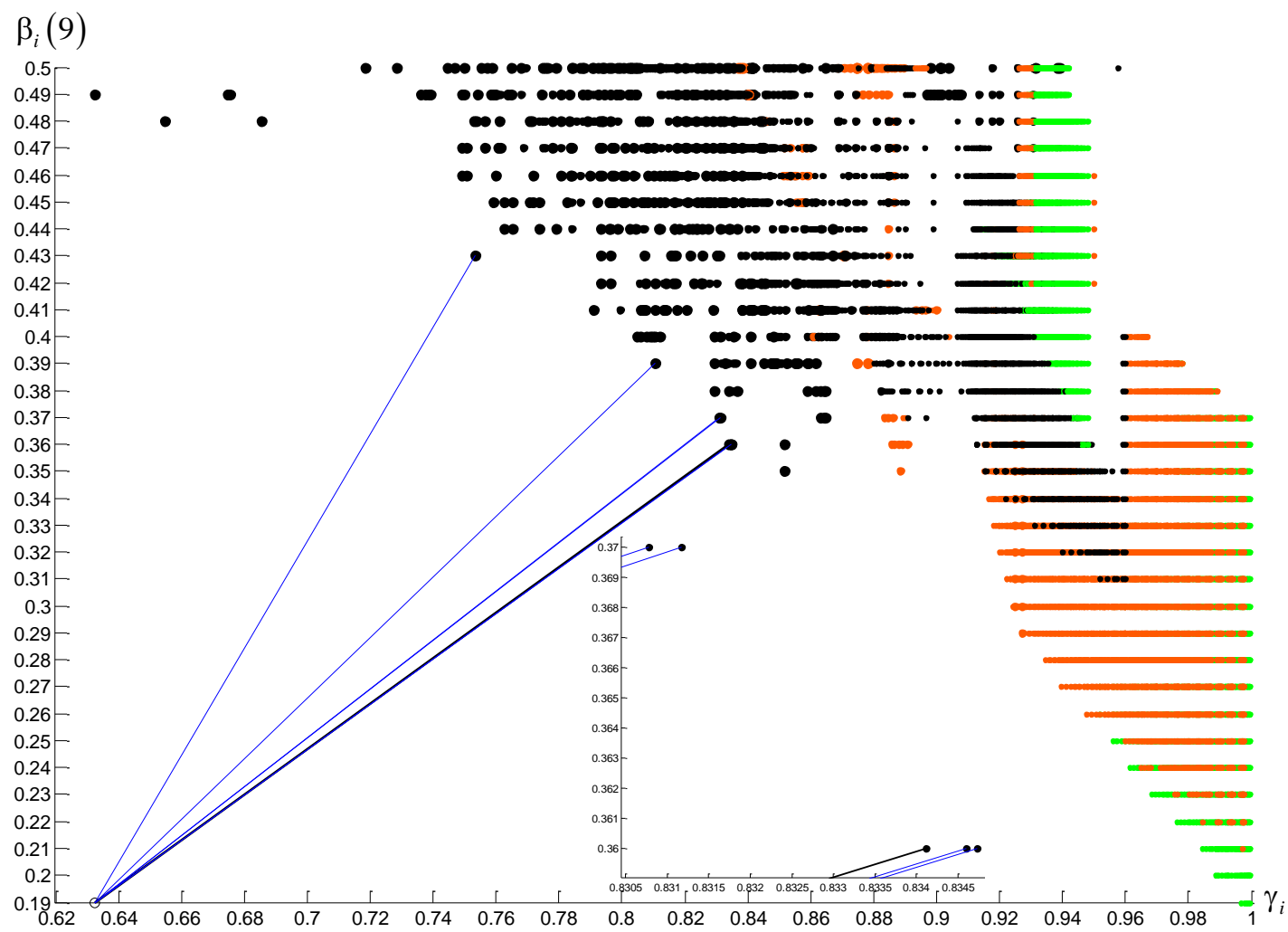

Figure 13. Acceptable costs and concessions among these 7 versions of best couples (Eq. 27), where just 2 versions (the 2 lines above) are excluded; the corresponding fines are light (there is a version wherein the 2-fine is 0.34 and the 3-fine is 0.986, i.e. even lesser than the cost of application of a water treatment system) 


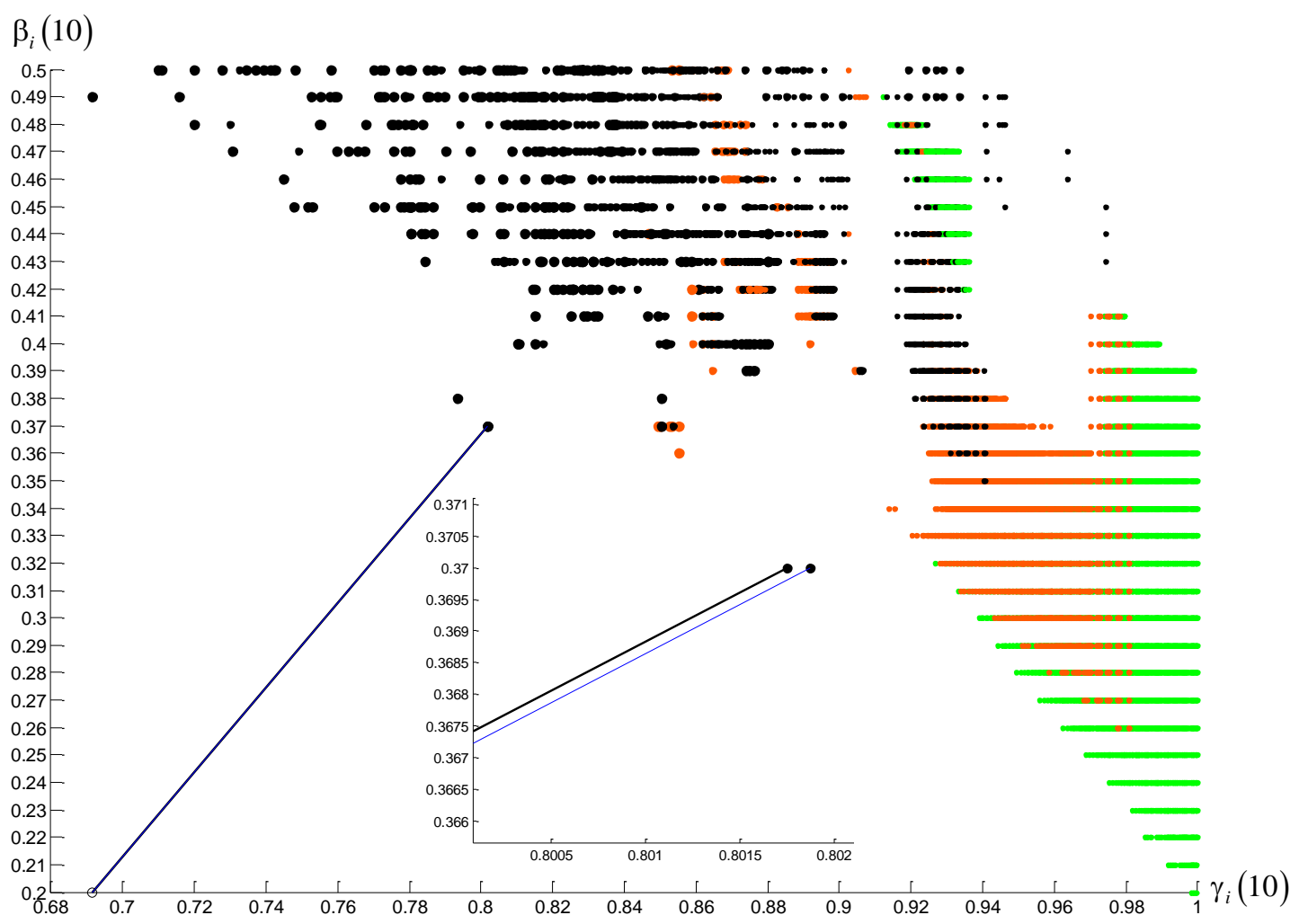

Figure 14. After the tightest sampling, here are only 2 versions of best couples (Eq. 27) including couple (Eq. 29) by both acceptable costs and concessions; the corresponding fines are close to the relatively lightest

The best couple of the cost and concession can be found by its index (a subset number in Table 1)

$$
i^{* * * * *} \in \arg \underset{\left\{i^{* *}=1,\left|L_{*}(M)\right|_{M=4}^{10}\right.}{ } \sqrt{\left(\gamma_{i^{* *}}^{*}(M)-\gamma_{\text {min }}^{*}\right)^{2}+\left(\beta_{i^{* *}}^{*}(M)-\beta_{\text {min }}^{*}\right)^{2}}
$$

independently of $M$, where distance

$$
\rho_{i^{* *}}^{\langle\min \rangle}(M)=\sqrt{\left(\gamma_{i^{* *}}^{*}(M)-\gamma_{\min }^{*}\right)^{2}+\left(\beta_{i^{* *}}^{*}(M)-\beta_{\min }^{*}\right)^{2}}
$$

similarly to (Eq. 26), for $i^{* *}=\overline{1,\left|L_{*}(M)\right|}$ and $M=\overline{4,10}$.

Distances (Eq.32) are shown against the subset number (rows in Table 1) in Figure 15. It is roughly seen that as sampling becomes more compact (being tightened) both cost and concession tend to decrease. The best couple of the cost and concession has index $i^{* * *}=1$ for $M=10$ (row \#30 in Table 1) whereas

$$
\rho_{1}^{\langle\min \rangle}(10) \approx 0.2373
$$

but 


$$
\rho_{2}^{\langle\min \rangle}(10) \approx 0.2374
$$

for row \#31 in Table 1. Therefore, the corresponding fines are $a_{1}^{*}(10)=0.34$ and $b_{1}^{*}(10)=1.394$, which allow every subject paying 0.8018 units by conceding 0.37 units to make situation

$$
\left\{d_{1}^{\langle 0.37\rangle}, d_{2}^{\langle 0.37\rangle}, d_{3}^{\langle 0.37\rangle}\right\}=\{3 / 10,3 / 10,3 / 10\}
$$

at $M=10$ the best approximate equilibrium.

Table 1. The list of subsets (Eq. 30) along with distances (Eq. 31) by (Eq. 26), where rows with best distances for its sampling are highlighted bold (all 31 rows correspond to the linking lines in Figs. 8-14)

\begin{tabular}{c|c|c|c|c|c|c|c}
\hline Subset \# & $M$ & $\begin{array}{c}\text { Probability of } \\
\text { discharging } \\
\text { without treatment }\end{array}$ & Cost & Concession & 2-fine & 3-fine & $\begin{array}{c}\text { Distance } \\
\text { by (Eq. 26) }\end{array}$ \\
\hline 1 & 4 & $1 / 4$ & 0.9425 & 0.3400 & 0.8800 & 4.4000 & 0.0903 \\
2 & $\mathbf{4}$ & $\mathbf{1 / 4}$ & $\mathbf{0 . 9 4 6 9}$ & $\mathbf{0 . 3 3 0 0}$ & $\mathbf{0 . 9 0 0 0}$ & $\mathbf{4 . 5 0 0 0}$ & $\mathbf{0 . 0 8 9 1}$ \\
3 & 4 & $1 / 4$ & 0.9476 & 0.3300 & 0.9100 & 4.4590 & 0.0898 \\
4 & 4 & $1 / 4$ & 0.9513 & 0.3200 & 0.9200 & 4.6000 & 0.0892 \\
5 & 4 & $1 / 4$ & 0.9484 & 0.3300 & 0.9200 & 4.4160 & 0.0904 \\
6 & 4 & $1 / 4$ & 0.9520 & 0.3200 & 0.9300 & 4.5570 & 0.0899 \\
7 & 4 & $1 / 4$ & 0.9556 & 0.3100 & 0.9400 & 4.7000 & 0.0906 \\
8 & 4 & $1 / 4$ & 0.9527 & 0.3200 & 0.9400 & 4.5120 & 0.0905 \\
9 & 5 & $1 / 5$ & 0.9319 & 0.4300 & 0.9700 & 4.8500 & 0.0270 \\
10 & $\mathbf{5}$ & $\mathbf{1 / 5}$ & $\mathbf{0 . 9 3 1 7}$ & $\mathbf{0 . 4 3 0 0}$ & $\mathbf{0 . 9 8 0 0}$ & $\mathbf{4 . 7 0 4 0}$ & $\mathbf{0 . 0 2 6 8}$ \\
11 & 5 & $1 / 5$ & 0.9323 & 0.4300 & 0.9900 & 4.6530 & 0.0273 \\
12 & $\mathbf{6}$ & $\mathbf{1 / 3}$ & $\mathbf{0 . 7 9 2 5}$ & $\mathbf{0 . 4 1 0 0}$ & $\mathbf{0 . 3 9 0 0}$ & $\mathbf{1 . 1 7 0 0}$ & $\mathbf{0 . 2 8 9 6}$ \\
13 & 6 & $1 / 3$ & 0.7950 & 0.4100 & 0.4000 & 1.1600 & 0.2912 \\
14 & 6 & $1 / 3$ & 0.7973 & 0.4100 & 0.4100 & 1.1480 & 0.2927 \\
15 & 6 & $1 / 3$ & 0.7993 & 0.4100 & 0.4200 & 1.1340 & 0.2940 \\
16 & 6 & $1 / 3$ & 0.8010 & 0.4100 & 0.4300 & 1.1180 & 0.2952 \\
17 & 7 & $2 / 7$ & 0.8043 & 0.4400 & 0.3400 & 1.5980 & 0.2609 \\
18 & 7 & $2 / 7$ & 0.8056 & 0.4400 & 0.3500 & 1.5750 & 0.2615 \\
19 & 7 & $2 / 7$ & 0.8066 & 0.4400 & 0.3600 & 1.5480 & 0.2620 \\
20 & $\mathbf{7}$ & $2 / 7$ & $\mathbf{0 . 7 5 4 4}$ & $\mathbf{0 . 4 6 0 0}$ & $\mathbf{0 . 3 6 0 0}$ & $\mathbf{0 . 9 3 6 0}$ & $\mathbf{0 . 2 6 0 5}$ \\
21 & $\mathbf{8}$ & $\mathbf{1 / 4}$ & $\mathbf{0 . 8 3 3 6}$ & $\mathbf{0 . 4 5 0 0}$ & $\mathbf{0 . 4 3 0 0}$ & $\mathbf{1 . 8 0 6 0}$ & $\mathbf{0 . 1 7 3 0}$ \\
22 & 8 & $1 / 4$ & 0.8361 & 0.4500 & 0.4400 & 1.8040 & 0.1740 \\
23 & 9 & $1 / 3$ & 0.8108 & 0.3900 & 0.3400 & 1.6320 & 0.2679 \\
24 & 9 & $1 / 3$ & 0.7534 & 0.4300 & 0.3400 & 0.9860 & 0.2687 \\
25 & $\mathbf{9}$ & $1 / 3$ & $\mathbf{0 . 8 3 4 1}$ & $\mathbf{0 . 3 6 0 0}$ & $\mathbf{0 . 3 8 0 0}$ & $\mathbf{1 . 7 4 8 0}$ & $\mathbf{0 . 2 6 3 7}$ \\
26 & 9 & $1 / 3$ & 0.8308 & 0.3700 & 0.3800 & 1.7100 & 0.2677 \\
27 & 9 & $1 / 3$ & 0.8346 & 0.3600 & 0.3900 & 1.7160 & 0.2640 \\
28 & 9 & $1 / 3$ & 0.8312 & 0.3700 & 0.3900 & 1.6770 & 0.2680 \\
29 & 9 & 1.3 & 0.8347 & 0.3600 & 0.4000 & 1.6800 & 0.2641 \\
30 & $\mathbf{1 0}$ & $\mathbf{3 / 1 0}$ & $\mathbf{0 . 8 0 1 8}$ & $\mathbf{0 . 3 7 0 0}$ & $\mathbf{0 . 3 4 0 0}$ & $\mathbf{1 . 3 9 4 0}$ & $\mathbf{0 . 2 0 2 6}$ \\
31 & 10 & $3 / 10$ & 0.8019 & 0.3700 & 0.3500 & 1.3650 & 0.2026 \\
\hline & & & & & &
\end{tabular}




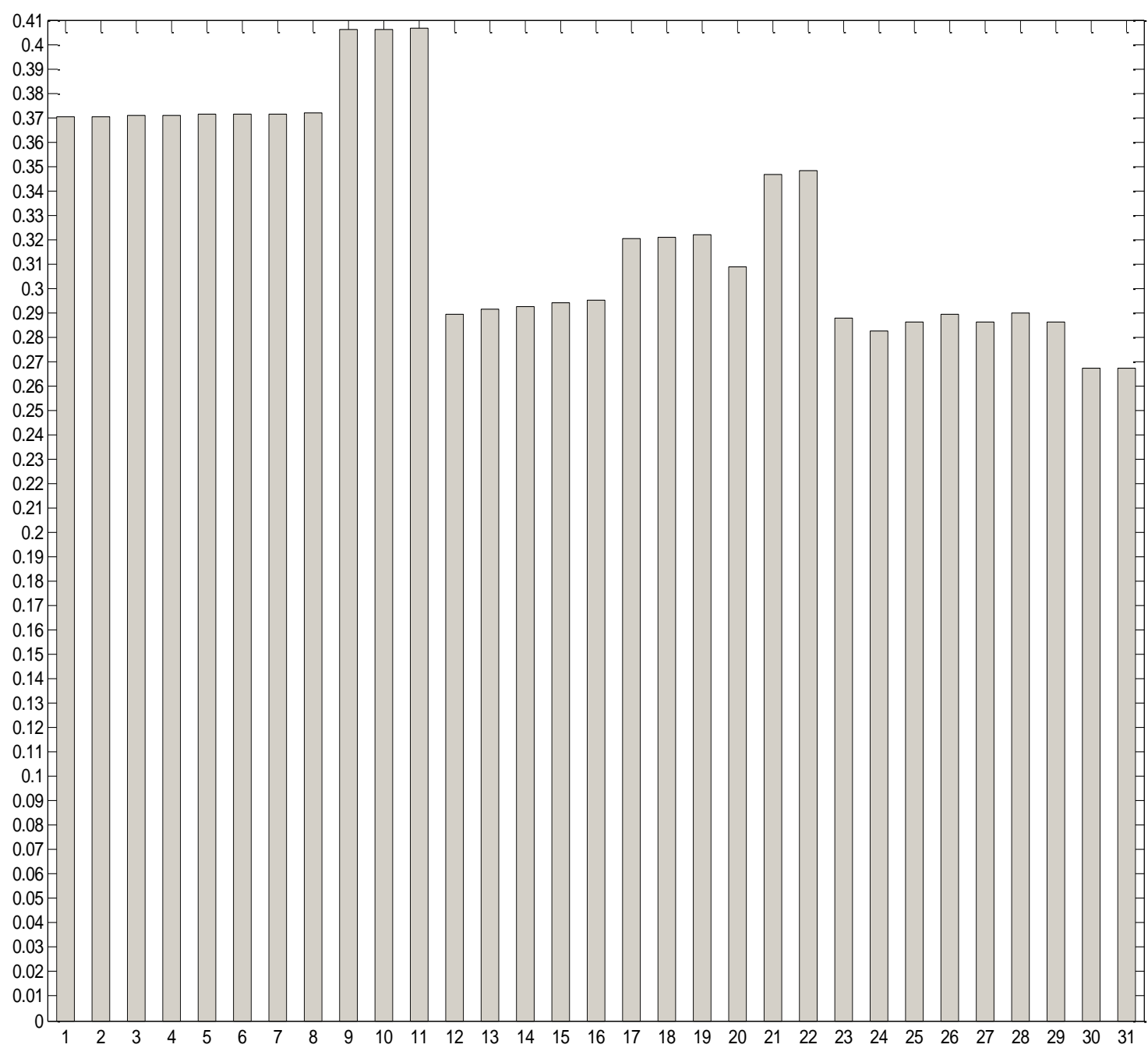

Figure 15. Distances (Eq. 32) against the subset number (row) in Table 1

Row \#31 corresponds to approximate equilibrium (Eq. 33) also. The only difference is a slightly greater cost ( 0.8019 units). This is caused by a slight increment of the 2 -fine (by 0.01 units). Amazingly enough, the 3 -fine here is decreased more (by 0.029 units, which is $2.1 \%$ ).

\section{Discussion}

First of all, it must be mentioned that subjects are not tied to any sampling, or to concessions. Moreover, the subjects may do not "know" the probability 0.3, not speaking about situation (Eq. 34). Hence, the sampling at $M=10$, which has appeared to be the best according with distance (Eq. 33), should be imposed on the subjects. This implies that some conditions are to be established by which switching from "clean" to "polluting" manufacturing and backwards will be controlled exactly once per those 10 periods of time (10 days, weeks, or months), where the fastest switch is possible only after one period. Such controlling will allow seeing how many times each of the subjects switches per every 10 times. Once a recommendation of holding to the probability 0.3 is given (by which the water treatment system is turned off for 3 periods 
of 10), the environmental pollution subject is able to control it itself. Prior to that, the 2-fine is set at 0.34 units. This is the lowest rate of fining when only two subjects do simultaneously not treat wastewater. The 3 -fine is set at 1.394 units, which is 4.1 times greater than the 2-fine, but it is not as heavy as it could have been. Nevertheless, this is enough preventive from bad pollution. Under threat of the heavy 3-fine, the subjects will definitely come to a convention of scheduling the water treatment systems. After every 10 periods of time, the grand total of 2-fines is 3.4 units per subject, and the grand total of 3-fines is 13.94 units per subject. Eventually, the cost of 8.018 units for a subject is just the expected spendings, whereas the least cost in 7 units is still possible. For instance, if a permanent schedule of water treatment is approved and followed (Table 2), then it costs the least for all.

Table 2. An example of scheduled water treatment $(1-$ water treatment system is applied, 0 - water treatment system is turned off, * - obligatory control and fining, if there are violations)

\begin{tabular}{c|c|c|c|c|c|c|c|c|c|c|c|c|c|c}
\hline Period \# & $1 *$ & 2 & 3 & 4 & 5 & 6 & 7 & 8 & 9 & 10 & $1 *$ & 2 & 3 & $\ldots$ \\
\hline Subject \#1 & 1 & 1 & 1 & 1 & 1 & 1 & 0 & 0 & 0 & 1 & 1 & 1 & 1 & $\ldots$ \\
\hline Subject \#2 & 1 & 1 & 1 & 0 & 0 & 0 & 1 & 1 & 1 & 1 & 1 & 1 & 1 & $\ldots$ \\
\hline Subject \#3 & 0 & 0 & 0 & 1 & 1 & 1 & 1 & 1 & 1 & 1 & 0 & 0 & 0 & $\ldots$ \\
\hline
\end{tabular}

The suggested model along with approximate equilibrium (Eq.34) can be useful especially for triples of industrial enterprises which are not situated in one country but use the same river water (such as the Danube, Tisza, Rhine, etc.). It is easy to implement this model across countries of the European Union using the same currency (the euro is the official currency in 19 of 28 member states of the European Union, as well as in some of the territories of the Union) and thus sharing the analogous background (Guo, 2018). Countries with different currencies are neighbors anyway, so discrepancies in exchange rate are not dramatic, and standardization to the conventional units is realizable (Wolf, 2009). Although a source of pollution could be determined easier for this case, it will always take additional costs from governments. Even if measurements of a water pollution rate along with some complex investigations could reveal which subject is "clean" and which subjects work "polluted", the process of eventual compensation might be badly lingered after suing (e.g. see the undecided tri-state water dispute described by Jordan and Wolf, 2006).

From the other side, a single enterprise may have its capacities allocated in various sites of the same reservoir. In such a case, those capacities can be grouped into three clusters, similar to each other, and the suggested model becomes applicable.

\section{Conclusion}

Generally, the environmental protection model in the form of the considered dyadic 3 -person game is a basis for two balances. The first novelty is the ecologically healthy water balance maintained via a policy of approximate equilibrium (Eq. 34). The second novelty, but it is not less important, is that rationally substantiated fines allow environmental pollution subjects to function stably. Although concessions in (Eq. 34) may be thought as a destabilizing factor, they eventually mean that a seductive 
possibility to pay 3.7 units less (after the next 10 periods) will disappear as quickly as other subjects start violating. Therefore, the concessions are a deterrent factor rather than a seduction to decrease costs. Conceding is just a primary advantage, which will be destroyed once a control is executed. Thus, approximate equilibrium (Eq. 34) becomes really stable. This is realized by the balanced (economically more reasonable) fines, which also merge stable functioning of environmental pollution subjects with the ecologically healthy water balance.

In terms of legal theory, the suggested model is an environmental law based on rigorous inferences from stability, rationality, and non-biased profitability. It may serve as a substantiation as for small environmental conventions (within one country), as well as for international conventions (e.g. like the Kyoto Protocol and the mentioned Water Convention). This is quite tractable owing to that the model-based decisions are not only prescriptive and constraining but also are motivating to environmental protection.

\section{REFERENCES}

[1] Arguedas, C. (2013): Pollution standards, technology investment and fines for non-compliance. - Journal of Regulatory Economics 44(2): 156-176.

[2] Beiras, R. (2018): Liquid Wastes: From Self-Purification to Waste Water Treatment. In: Beiras, R. (ed.) Marine Pollution. Elsevier, Amsterdam, pp. 53-67.

[3] Cui, X., Wu, X., He, X., Li, Z., Shi, C., Wu, F. (2018): Regional suitability of virtual water strategy: evaluating with an integrated water-ecosystem-economy index. - Journal of Cleaner Production 199: 659-667.

[4] Guo, R. (2018): Cross-Border Resource Management (Third Edition). - Elsevier, Amsterdam.

[5] Heyes, A. G. (2000): Implementing environmental regulation: enforcement and compliance. - Journal of Regulatory Economics 17: 107-129.

[6] Hussain, T., Wahab, A. (2018): A critical review of the current water conservation practices in textile wet processing. - Journal of Cleaner Production 198: 806-819.

[7] James, D. (2017): The Role of Economic Analysis in Water Resource Management - The Murray-Darling Experience. - In: Hart, B. T., Doolan, J. (eds.) Decision Making in Water Resources Policy and Management. Academic Press, Cambridge, MA, pp. 133-149.

[8] Jiménez, S., Micó, M. M., Arnaldos, M., Medina, F., Contreras, S. (2018): State of the art of produced water treatment. - Chemosphere 192: 186-208.

[9] Jordan, J. L., Wolf, A. T. (2006): Interstate Water Allocation in Alabama, Florida, and Georgia: New Issues, New Methods, New Models. - University Press of Florida, Gainesville.

[10] Mousavi, S., Kara, S., Kornfeld, B. (2015): Assessing the impact of embodied water in manufacturing systems. - Procedia CIRP 29: 80-85.

[11] Parimal, P. (2017): Sustainable Water-Treatment Technology. - In: Parimal, P. (ed.) Industrial Water Treatment Process Technology. Butterworth-Heinemann, Oxford, UK, pp. 565-571.

[12] Regens, J. L., Seldon, B. J., Elliott, E. (1997): Modeling compliance to environmental regulation: Evidence from manufacturing industries. - Journal of Policy Modeling 19(6): 683-696.

[13] Rey, A., Basurko, O. C., Rodríguez-Ezpeleta, N. (2018): The challenges and promises of genetic approaches for ballast water management. - Journal of Sea Research 133: 134-145.

[14] Romanuke, V. V. (2009): Practical realization of the strategy in the most advantageous symmetric situation of the dyadic game with the three subjects of the reservoir pollution. - Ecological Safety 4(8): 49-56. 
[15] Romanuke, V. V. (2010a): Recommendations on using the nonequilibrium symmetric situation in a dyadic game as a model of the environment preservation with the three subjects of pollution. - Ecological Safety and Nature Management 5: 144-159.

[16] Romanuke, V. V. (2010b): Environment guard model as dyadic three-person game with the generalized fine for the reservoir pollution. - Ecological Safety and Nature Management 6: 77-94.

[17] Romanuke, V. V. (2016): Approximate equilibrium situations with possible concessions in finite noncooperative game by sampling irregularly fundamental simplexes as sets of players' mixed strategies. - Journal of Uncertain Systems 10(4): 269-281.

[18] Sgroi, M., Vagliasindi, F. G. A., Roccaro, P. (2018): Feasibility, sustainability and circular economy concepts in water reuse. - Current Opinion in Environmental Science \& Health 2: 20-25.

[19] Skouteris, G., Ouki, S., Foo, D., Saroj, D., Altini, M., Melidis, P., Cowley, B., Ells, G., Palmer, S., O'Dell, S. (2018): Water footprint and water pinch analysis techniques for sustainable water management in the brick-manufacturing industry. - Journal of Cleaner Production 172: 786-794.

[20] Vorob'yov, N. N. (1984): Game Theory Fundamentals. Noncooperative Games. - Nauka, Moscow (in Russian).

[21] Wolf, A. T. (2009): International Water Convention and Treaties. - In: Likens, G. E. (ed.) Encyclopedia of Inland Waters. Academic Press, Cambridge, MA, pp. 286-294.

[22] Xu, J., Hou, S., Xie, H., Lv, C., Yao, L. (2018): Equilibrium approach towards water resource management and pollution control in coal chemical industrial park. - Journal of Environmental Management 219: 56-73.

[23] Zikos, D., Hagedorn, K. (2017): Competition for Water Resources from the European Perspective. - In: Ziolkowska, J. R., Peterson, J. M. (eds.) Competition for Water Resources. Elsevier, Amsterdam, pp. 19-35.

[24] Zomorodian, M., Lai, S. H., Homayounfar, M., Ibrahim, S., Fatemi, S. E., El-Shafie, A. (2018): The state-of-the-art system dynamics application in integrated water resources modeling. - Journal of Environmental Management 227: 294-304. 